تاريخ الإرسال (28-04-2020)، تاريخ قبول النشر (19-05-2020)

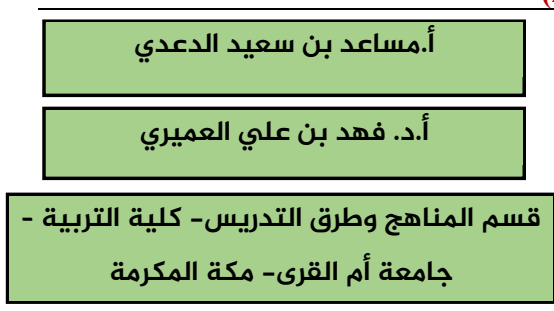

* البريد الالكتروني للباحث المرسل:

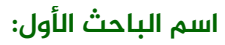

اسم الباحث الثاني: - اسن

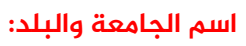

$$
\begin{aligned}
& \text { تصميه برنامج تعليمي مقترح قتائم على الخرائط } \\
& \text { الر قبية وقياس فاعليته في تنمية مفاهيه }
\end{aligned}
$$

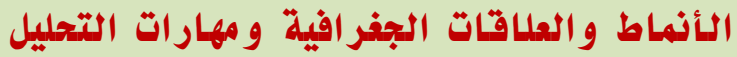

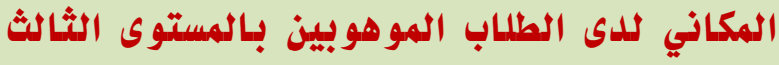

$$
\begin{aligned}
& \text { الثانوي في مدينة مكة المكرمة }
\end{aligned}
$$

E-mail address:

Msd-11@hotmail.com

https://doi.org/10.33976/IUGJEPS.29.2/2021/33

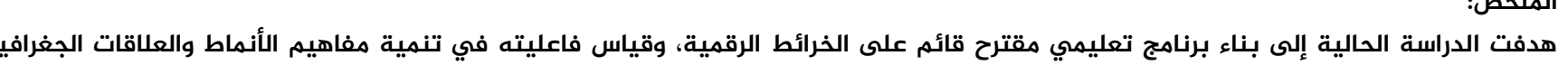

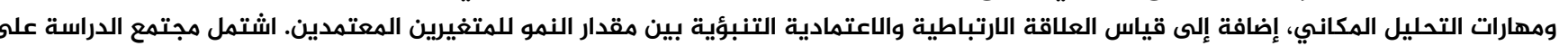

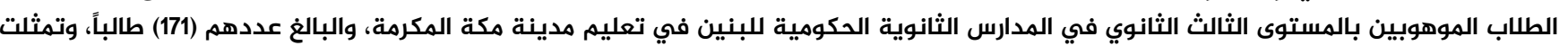

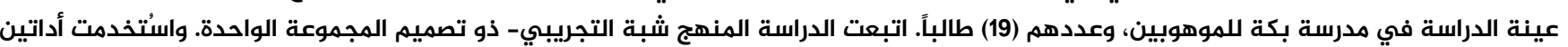

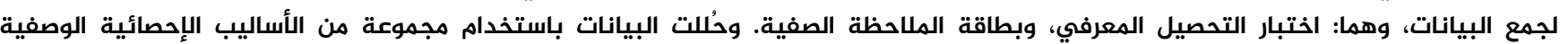

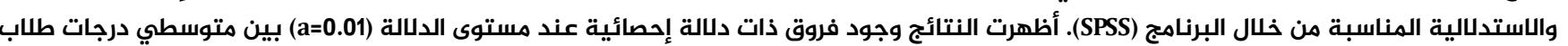

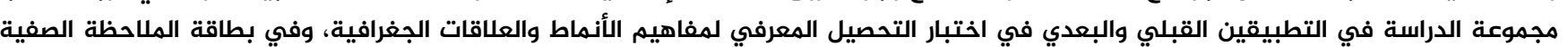

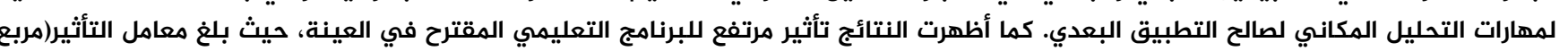

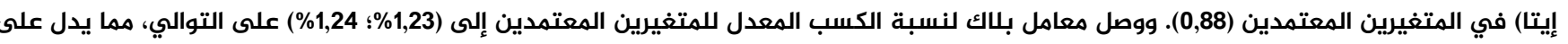

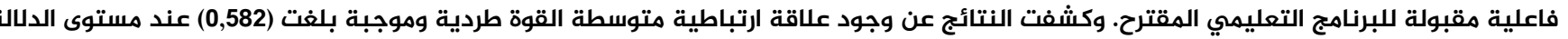

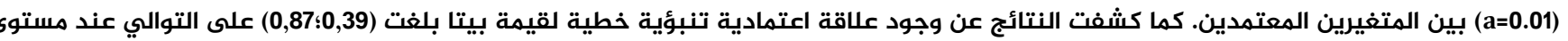

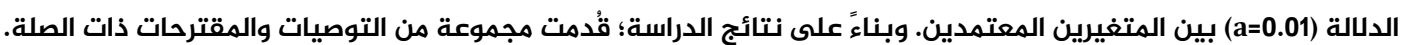

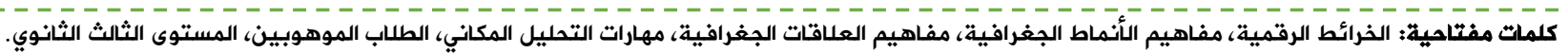

Designing a Designing a suggested educational program on digital maps and measuring its effectiveness in developing concepts of patterns, geographic relationships and spatial analysis skills for gifted students at the third secondary school level in the city of Makkah Al-Mukarramah

Abstract:

The current study aims at Designing a proposed educational program based on digital maps, and measuring its effectiveness in developing concepts of patterns, geographical relations and spatial analysis skills, in addition to, measuring the correlation and predictive dependence between the amount of growth for the approved variables. The study community included (171) gifted male students at the third secondary school level at government secondary schools, in the city of Makkah Al-Mukarramah, and the sample of the study was applied to (19) male students in Bakkah School for the gifted students. The study followed the semi-experimental curriculum - one group design. Two tools were used to collect data: the cognitive achievement test and the grade note card. The data were analyzed using a set of appropriate descriptive and inferential statistical methods through the SPSS program. The results showed that there are statistically significant differences at the level of significance $(\mathrm{a}=0.01)$ between the mean scores of the study group students in the pre and post applications in the cognitive achievement test for the concepts of patterns and geographical relations and in the class note card for the spatial analysis skills in favor of the post application. A high impact of the proposed educational program with the sample, where the effect coefficient (ETA coefficient) for each of the approved variables was (0.88). Blake coefficient of the modified gain ratio for the approved variables reached $(1.23 \%$ and $1.24 \%)$, respectively. This indicates an acceptable effectiveness of the proposed educational program results of the presence positive correlative correlation of value of $(0.582)$ at

the level of significance $(a=0.01)$ between the two approved variables. The results also revealed a linear predictive correlation of beta value of $(0.39 ; 0.87)$ on the sequence at the significance level $(\mathrm{a}=0.01)$ between the two approved variables. Based on the results of the study, a set of related recommendations and suggestions were presented.

Keywords: Digital Maps, Concepts of Geographical Patterns, Concepts of Geographical Relations, Skills of Spatial Analysis, Gifted Students, The third Secondary Level. 
يعتقد الكثير من الناس أن الجغرافيا سهلة التعلم، وأن ذلك في نظرهم كافي لتعلم معلومات جديدة أساسية، ولكن الواقع ليس كذلك، فالجغرافيا هي موضوع معقد ومستع ومتشعب، لأنها تتناول موضوعات دئ تلضمن الأنظمة الطبيعية المتداخلة مع الأنسان

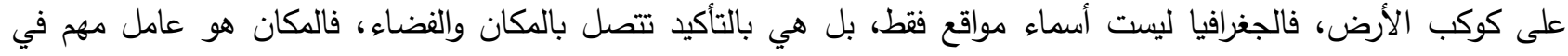

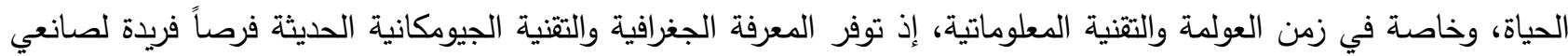

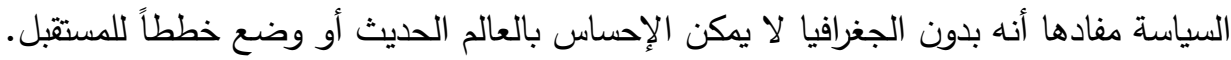

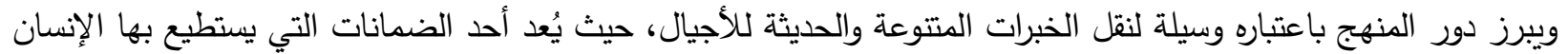

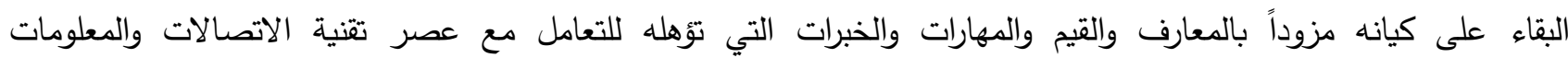
(الحربي،2016؛ العميري، 2019). وبما أن المناهج وبخاصة مناهج الموهوبين تعالج قضايا متغيرة؛ فإن تحديثها وإثراءها

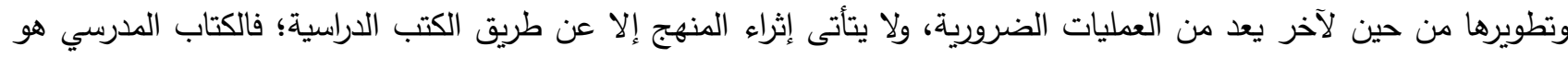

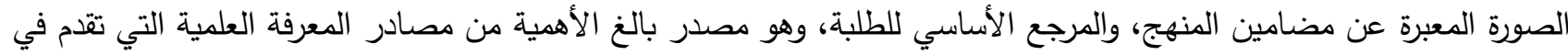

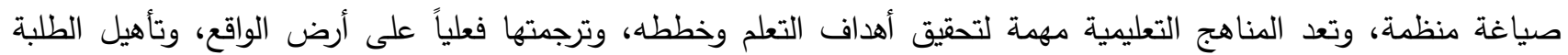

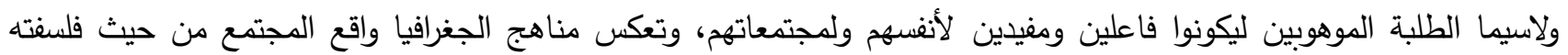

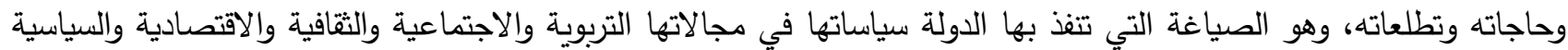
(النادي،2007؛ العميري والطلحي، 2019). وبناءً على ذلك؛ تسعى المؤسسات التربوية جاهدة إلى بناء المناهج التي تتواكب مع التوجهات والتطورات الحديثة إضافة إلى إعداد وتدريب جيل من المعلمين التقنيين المبدعين، الذين يمارسون أدواراً حديثة يصبح الطلبة فيها محور العملية التعليمية التعلمية، وعليهم يقع الدور الأكبر في إحداث التعلم، وبذلك يصبح دور المعلم ميسر وموجه ومرشد لمضامين المنهج المدرسي ومهيئ للبيئة

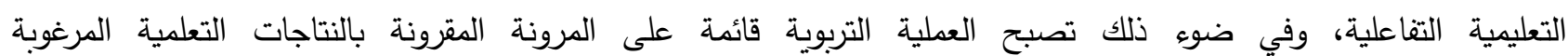
.(Ghaith,2003)

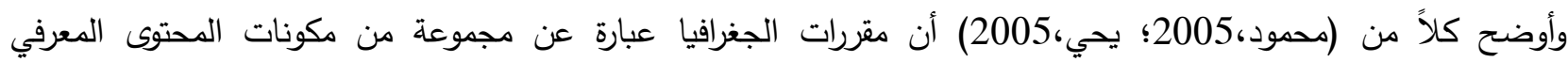

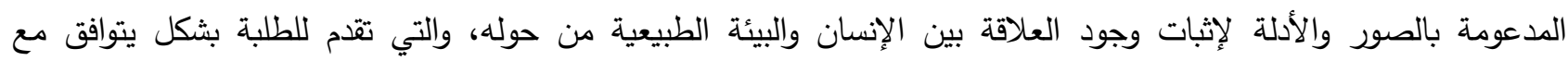

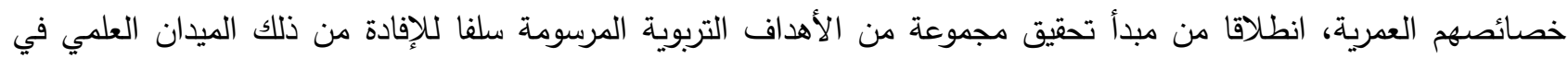

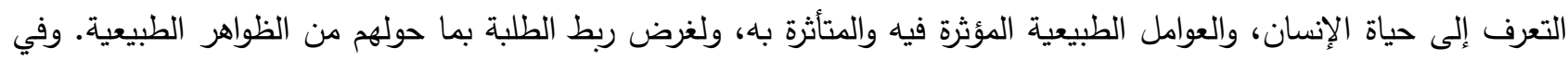

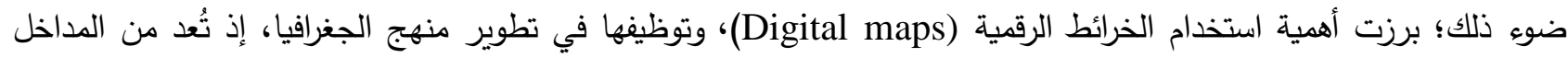

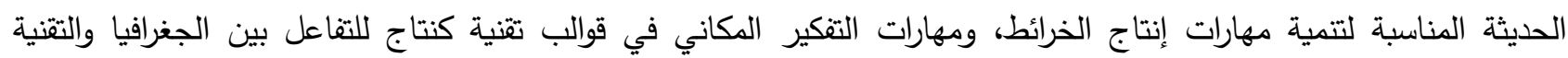
الحديثة (كاظم وعبيد، 2014؛ عودة، 2015). ويتمحر دور الخرائط الرقمية في مساعدة الطلبة وخاصة الطلبة الموهوبين في استكثاف وتحليل النماذج المرئية التي تظهر

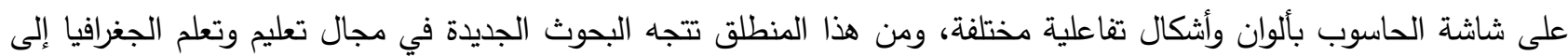

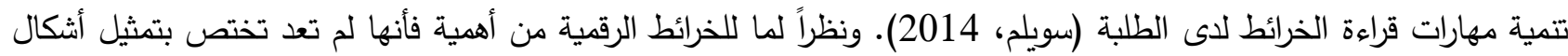

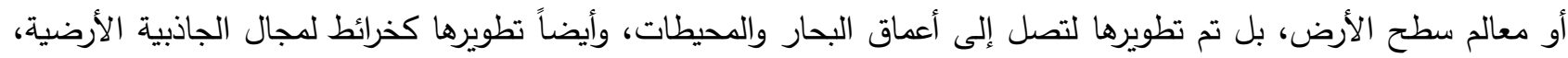

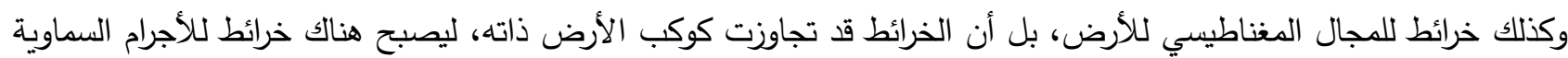
(داوود،2012؛؛ عمار 2013) ويعتقد الجغرافيون أن التعرف إلى الأنماط الجغرافية هو نقطة البداية الضرورية لفهم كيف يعيش الناس على سطح الأرض، ولقد

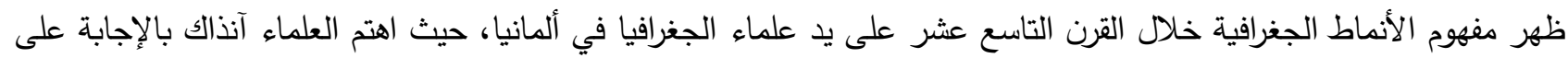
سؤال رئيس ألا وهو: لماذا تقع الأشياء في مكانها. ويعرف أبو صبحة (2015،51) الأنماط المكانية أنها: "الطريقة التي تتنظم 
بها الخصائص المكانية، ويتم تحديدها من خلال تحليل العلاقات الرأسية بين الغطاء السكاني من الأعلى والبيئة الجغرافية من الأسفل، للوصول ترتيب أو تتظيم الخصائص المكانية أي الكثف عن الأنماط المكانية التي تتنظم بها هذه الخصائص".

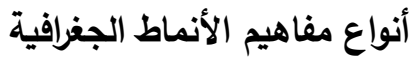
يثير كلاً من (العميري،2004؛ الغزاوي،2006؛ مدخلي،2014؛ الحارثي،2015) إلى أنواع مفاهيم الأنماط الجغرافية، وهي كالاتي: 1- النمط المنتظ: النمط الذي يمتاز بانتشار الظواهر الطبيعية والبشرية في الحيز المكاني بصورة تتسم بالترتيب والتتسيق،

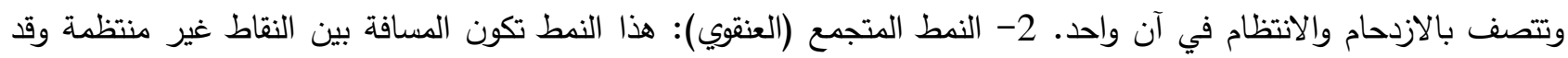
يأخذ التوزيع المكاني في النمط المتجمع شكل متقارب. 3- النمط المتكتل: نمط قريب الثبه بالنمط العنقودي المتجمع، إلا أنه يختلف معه في أنه يعبر عن عناصر موضعية متكتلة تتمركز في قسم محدود من منقطة معينة، بينما تخلو بقية المنطقة من تلك بكابك

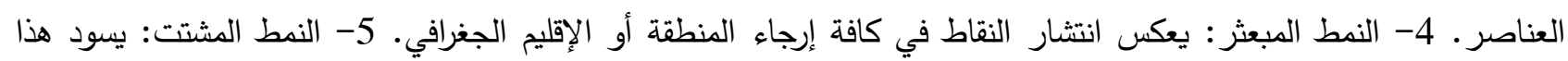
النمط عندما يكون امتداد الأرض على شكل طولي أو عر ضي مثل افغانستان والكونغو. 6- النمط الثعاعي: يستخدم هذا النمط بشكل خاص في تحديد توزيع الظواهر المكانية وفقاً لامتداد طرق المواصلات، حث أنه في هذا النمط تمتد الشوارع الرئيسية من مركز المدينة نحو اطرافها، على هيئة شعاعية. 7- نمط الانتشار الخطي أو الطولي: تتنظم الظواهر الجغرافية أو التوزيع السكاني على شكل امتداد خطي مثل التهاعل امتداد المجاري المائية. 8- النمط المجزأ: يكون هذا النمط غالباً في الدول الجُزرية التي تحتوي على عدد كبير من الجزر مثل اندونيسيا والثلبين. 9- النمط المركب: النمط الذي يجمع بين تصنيفين من الظواهر الطبيعية والبشرية. 10- نمط الثكل الدائري: يستخدم هذا النمط بشكل خاص في الجغرافية السياسية. ويدرك الجغرافيون أن الظواهر التي تدخل في تكوين المنطقة أو الدكان أو الإقليم أو سطح الأرض لا توجد معزولة وإنما تتفاعل مع بعضها، وترتبط بعلاقات ينتج عنها تباينات بني المناطق، كما أن وصف الجغرافيا بأنها علم العلاقات المكانية. لذلك عرف (مدخلي،2014،8) العلاقات الجغرافية بأنها:" المفاهيم التي تهتم بإدراك العلاقات بين الظواهر على الخريطة، والقدرة على فهم الظواهر المتمثلة على الخريطة، ومعرفة أبعادها والتأثير بينها". ونظراً لأهمية الدكان في الفكر الجغرافي لم يعد عبارة عن دراسة الإقليم أو المكان من وجهة نظر كون ذلك المكان صورة ساكنة، ولكن أضحى المكان وضعية متجددة متحركة تلتقي فيها مختلف العوامل التي تثكل باستمرار وجه الأرض، ومن هنا كانت الصفة الديناميكية لهذه الوضعيات المكانية موضوع دراسة الجغرافيا، بما تحتويه من علاقات مكانية (السامرائي،2015). وأورد كلاً من (أبو دلاح،2004؛ العميري،2004؛ الحارثي،2015؛(Buang \& Zakaria,2011) ، تصنيف العلاقات المكانية إلى عدة أصناف أساسية، وهي كالآتي: 1- العلاقة اللا ارتباطية: تتعلق بعدم انسجام أحد الظواهر المكانية مع باقي المكونات. 2- العلاقة التراكبية: التي تصف تداخل الظواهر المكانية في الحيز المكاني. 4- علاقة التغطية: هذه العلاقة يغطي مكون ما علي باقي الظواهر الموجودة في الحيز المكاني. 5- العلاقة الاحتوائية: تكون إحدى الظواهر المكانية هي القاعدة الأساس التي تقوم عليها باقي الظواهر . 6- العلاقة التوازنية: تقوم العلاقة بين الظواهر المكانية في هذا النوع على تساوي تأثير كل ظاهرة في باقي الظواهر المكانية. 7- العلاقات التسلسلية: يُقصد به طبيعة العلاقات التي تربط المفاهيم المكانية مع بعضها البعض من حيث التسلسل الهرمي لتلك المفاهيم. 
8- العلاقات التصنيفية: تخضع العلاقات بين المفاهيم لنوع معين من الرابط فيما بينها مثل الزمن، الكمية، الحجم، والملامح العامة. 9- العلاقات التتابعية: يتماز هذا النوع من العلاقات بأن حدوث ظاهرة ما، يعتمد على حدوث ظاهرة قبلها، أي أن حدوث الظواهر تأتي متتابعة وتعتمد كل ظاهرة على ما يسبقها من ظواهر . ويهتم علم الجغرافيا وتطبيقاته بالتوزيع الجغرافي للظاهرات وتحليلها على سطح الأرض، ويعرف الحميد والمسند (2012،34) التحليل المكاني بأنه: "منهجية تحليلية لتصميم قدرة موقع ما لدعم نشاط محدد كما أنه يعمل على دراسة العلاقات بين الخصائص الجغرافية للدراسات الطبيعية لموقع معين للتعرف على الميزات الكامنة به". وتتبع أهمية التحليل الكاني كونه يستخدم في كثير من المجالات أهمها علم الجغرافيا، فالتحليل المكاني أحدث فروع علم الجغرافيا وآخرها، وهنا يجدر القول بأن التحليل المكاني ليس حكراً على الجغرافيين فقط، فهو أسلوب لفهم عالمنا بشكل أفضل (البناي،2016). وبالرجوع إلى الأدب التربوي؛ فقد وجد مجموعة من الدراسات السابقة، المتصلة بالخرائط الرقمية كدراسة (Kerri, 2010) التي كثفت عن معرفة أثر استخدام برنامج قوقل الأرض (Google Earth) في محو الأمية المكانية وفهم الجغرافيا المكانية في تدريس الجغرافيا لدى طلاب المرحلة المتوسطة بولاية داكوتا الثمالية بالولايات المتحدة الأمريكية، واستخدم المنهج شبة التجريبي على عينة الدراسة المكونة من (48) طالباً، حيث تكونت مجموعة المقارنة من (44) طالباً درسوا بالصور ثنائية الأبعاد عن طريق عروض PowerPoint، ومجموعة الدراسة من (44) طالباً درسوا العالم باستخدام الخرائط ثلاثي الأبعاد عن طريق برنامج Google Earth لصالح مجموعة الدراسة؛ حيث تثير إلى أن الطلاب الذين استخدموا برنامج Google Earth تفوقوا على نظرائهم في مهارات التنبؤ، وفهم العلاقة المكانية. سعت دراسة كاربونيل وهيس (Carbonell \& Hess, 2019) التعرف إلى قياس فعالية بيئة ثلاثية الأبعاد تقوم على الخرائط الرقمية في تتمية مهارات التفكير المكاني، وتم استخدام المنهج شبه التجريبي -ذو تصميم المجموعة الواحدة. وتكونت العينة من (24) Map Topographic) طالبا بكلية الهندة بجامعة لاجونا في إسبانيا، وتم استخدام اختبار تقويم الخرائط الطبوغرافية يقيس التحليل المكاني قبل التجربة وبعدها، واستبانه لقياس أهمية التقنيات ثلاثية الأبعاد في تعليم الجغرافيا، كثفت

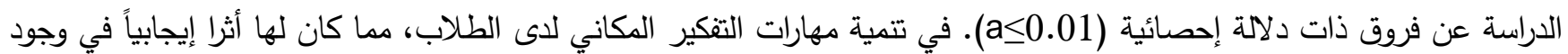
بيئة تعلم مبنية على برمجيات ثلاثية الأبعاد القائمة على الخرائط الرقمية. وفيما يتعلق بالدراسات المتصلة بمفاهيم الأنماط والعلاقات الجغرافية، فقد وُجد مجموعة من الدراسات السابقة كدراسة ستورز وكيلي وبراون (Sturz, Kelly \& Brown, 2009) عن دور الإثارات البصرية في تسهيل تعلم الأنماط والعلاقات المكانية بين المواقع، وذلك من خلال معرفة الآثار المترتبة على توظيف الإشارات البصرية في التعلم المكاني، واتبعت الدراسة المنهج شبة التجريبي، وطبقت الدراسة على عينة مكونة من (19) طالباً في إحدى المدارس الكندية، خضعوا للتدريب على توظيف الإثارات البصرية في بيئة

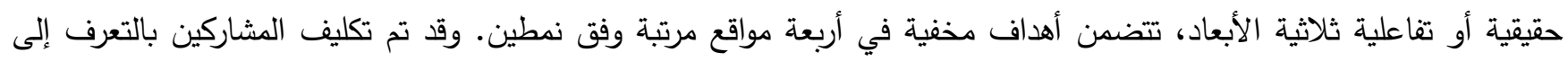
الأنماط والعلاقات المكانية من خلال الاستعانة بالإثارات البصرية، ثم تم اختبار الششاركين في غياب الإشارات البصرية. وأشارت

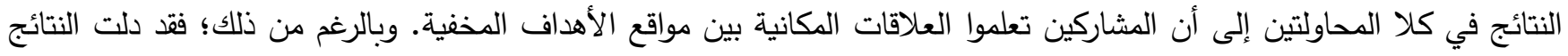
أن الإثارات البصرية أثناء التدريب سهلت تعلم الأنماط والعلاقات المكانية، حيث تبين أنها جعلت الأخطاء أقل أثناء الاختبار ، مقارنة بتعلم الأنماط والعلاقات المكانية في غياب الإثارات البصرية. 
وهدفت دراسة الحارثي (2015) إلى الكثف عن درجة امتلاك معلمي ومعلمات الدراسات الاجتماعية والوطنية بالمرحلة المتوسطة لكفاهيم الأنماط والعلاقات المكانية، ودرجة توظيفها في تدريسه، في ضوه جغرافية العولمة السياسية، وتكون مجتمع الدراسة من

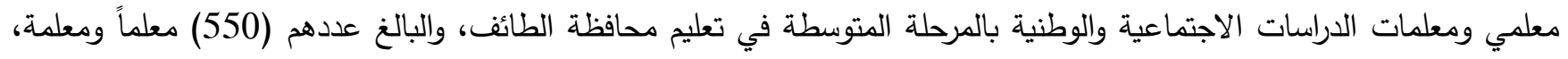
وبلغت العينة (163) معلماً ومعلمة. وقد اتبعت الدراسة المنهج الوصفي المسحي. واستخدمت لجمع البيانات الاستبانة وبطاقة الملاحظة. وكثفت نتائج استجابات المشاركين عن درجة امتلاك عينة الدراسة لمفاهيم الأنماط والعلاقات الجغرافية بدرجة منخفضة،

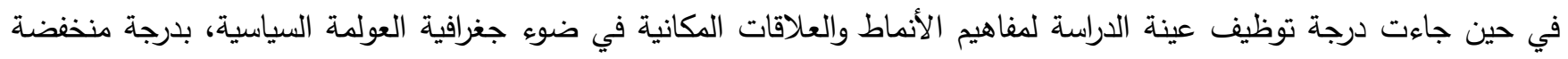
جداً. كما كثفت النتائج عن وجود فروق ذات دلالة احصائية عند مستوى الدلالة (as0.05) بين استجابات المشاركين في الدراسة وفقاً لمتغير التخصص الأكاديمي ولصالح تخصص الجغرافيا. وفيما يتعلق بالدراسات المتصلة بمهارات التحليل المكاني، فقد وُجد مجموعة من الدراسات السابقة كدراسة الأغا وأبو سالم (2018) التي كثفت عن أثر برنامج مقترح في تدريس الجغرافيا في تتمية مهارات قراءة الخريطة ومهارات الذكاء المكاني لاى طلاب الصف الثامن الأساسي بغزة في فلسطين، واتبعت الدراسة المنهج شبة التجريبي -ذو تصميم المجموعتين. وتكونت العينة من (70) طالباً، وتم تطبيق أداتين، وهما: اختبار مهارات قراءة الخريطة، واختبار مهارات الذكاء المكاني. وتوصلت نتائج الدراسة إلى وجود فروق دالة إحصائياً (a<0.01) بين المجموعتين لصالح مجموعة الدراسة. وهدفت دراسة (Almairi,2019) التعرف على تطور مهارات تعلم الجغرافيا لدى طلاب البكالوريوس واتجاهاتهم نحو العمل الحقلي كنتيجة لخبراتهم التي مارسوها في الرحلة الحقلية، وتكونت عينة الدراسة من (27) طالباً بقسم الجغرافيا في جامعة أم القرى بالمملكة العربية السعودية خلال الفصل الدراسي. وتم استخدام الاستبانة التي تكونت من (12) مهارة جغرافية لقياس تعلم الطلاب لهذه المهارات، أما التغير في اتجاهات الطلاب نحو العمل الحقلي فقد قيس من خلال النسخة المعدلة من مقياس بويل وآخرون (2007)، أيضا استخدمت المقابلة غير الرسمية كأداة ثالثة لجمع البيانات وذلك لتدعيم النتائج الكمية للدراسة. فكثفت النتائج أن جميع الطلاب طوروا مهاراتهم الجغرافية، حيث لوحظ أن سبع مهارات جغرافية، وهي: حل المشكلات، وأخذ العينات والقياسات وعمل التسجيل، وطرق إجراء المسوحات، وجمع المعلومات، وتحليل البيانات، والسلامة من المخاطر الحقلية، والتواصل وقابلية التحويل؛ تطورت لدى أكثر من (95\%) من الطلاب؛ بينما أجاب (92\%) منهم بتطور مهارتي الملاحظة، والتكامل؛ في حين أن مهارة التعرف على ونى الظاهرات الجغرافية تطورت لدى (90\%) من الطلاب؛ بينما شعر (89\%) من الطلاب بتطور مهارة تصميم التجارب الجغرافية، وأخيرا مهارة التفسير الجغرافي أتت بنسبة تطور بين الطلاب وصلت إلى (76\%). كما أظهرت المقارنة بين القياس القبلي والبعدي

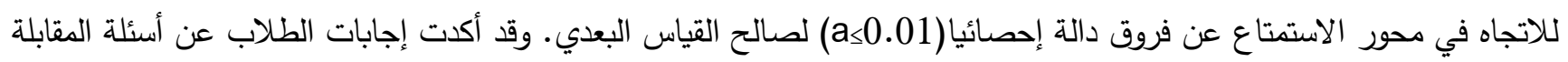
غير الرسمية نتائج الدراسة الكمية. مثكلة الدراسة: ظهرت في الآونة الأخيرة توجهات تربوية تدعم تطبيقات التقنيات الجغرافية في المرحلة الثانوية، كما هو الحال في نظم المعلومات الجغرافية (GIS)، والاستثعار عن بعد(RS) ، ونظام تحديد المواقع العالمي (GPS)، والتي يمكن تضمينها في الخرائط الرقمية (Digital Maps)، لتدعيم وتفعيل عملية تعليم وتعلم الموضوعات الجغرافية. وهذا ما أكدت عليه مجموعة من الدراسات الحديثة التي تتاولت التطبيقات التقنية في الجغرافيا (سويلم،2014؛ صالح،2017؛ السيد،2018؛ Mitchell, 2014 حيث أكدت جميعها على الأهمية التعليمية لتلك البرامج الجغرافية التقنية واتصافها بمخرجات مميزة. ومن خلال خبرة 777 IUG Journal of Educational and Psychology Sciences (Islamic University of Gaza) / CC BY 4.0 
الباحثين في هذا المجال، واطلاعهما المستمر على تطبيقات التقنيات الجغرافية، واستثارة المختصين في حقل الجغرافيا فقد لوحظ عدم وجود أي دراسة سابقة -على حد اطلاع الباحثين - اهتمت باستخدام الخرائط الرقمية في عملية تتمية مفاهيم الأنماط والعلاقات الجغرافية ومهارات التحليل المكاني. الأمر الذي يدل على وجود مشكلة تتمثل في غياب توظيف الخرائط الرقمية في مناهج الجغرافيا بالمرحلة الثانوية. ومن هنا انبثتت فكرة هذه الدراسة لبناء البرنامج التعليمي المقترح القائم على الخرائط الرقمية، ومن ثم قياس فاعليته في تتمية مفاهيم الأنماط والعلاقات الجغرافية ومهارات التحليل المكاني لاى الطلاب الموهوبين بالمرحلة الثانوية في المملكة العربية السعودية. أسئلة الاراسة وفرضياتها: 1- ما فاعلية البرنامج التعليمي المقترح القائم على الخرائط الرقمية في تتمية مفاهيم الأنماط والعلاقات الجغرافية لاى طلاب الموهوبين بالمستوى الثالث الثانوي في مدينة مكة المكرمة؟ 2- ما فاعلية البرنامج التعليمي المقترح القائم على الخرائط الرقمية في تتمية مهارات التحليل المكاني لاى الطلاب الموهوبين

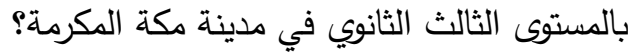
3- هل توجد علاقات ارتباطية واعتمادية تتبؤية بين مقدار النمو في مفاهيم الأنماط والعلاقات الجغرافية ومهارات التحليل المكاني لاى الطلاب الموهوبين بالمستوى الثالث في مدينة مكة المكرمة؟ وقد وضعت الفرضيات الصفرية بغية الإجابة عن أسئلة الدراسة، وهي كالآتي: 1- لا توجد فروق ذات دلالة إحصائية عند مستوى الدلالة (as0.05) بين متوسطي رتب مجموعة الدراسة في التطبيقين القبلي والبعدي لاختبار التحصيل المعرفي لمفاهيم الأنماط والعلاقات الجغرافية لدى الطلاب الموهوبين بالمستوى الثالث الثانوي في مدينة

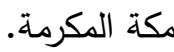
2- لا توجد فاعلية للبرنامج التعليمي المقترح القائم على الخرائط الرقمية في تتمية التحصيل المعرفي لمفاهيم الأنماط والعلاقات الجغرافية لاى الطلاب الموهوبين بالمستوى الثالث الثانوي في مدينة مكة المكرمة. 3- لا توجد فروق ذات دلالة إحصائية عند مستوى الدلالة (as0.05) بين متوسطي رتب مجموعة الدراسة في التطبيقين القبلي والبعدي لمهارات التحليل المكاني لدى الطلاب الموهوبين بالمستوى الثالث الثانوي في مدينة مكة المكرمة. 4- لا توجد فاعلية للبرنامج التعليمي المقترح القائم على الخرائط الرقمية في تتمية مهارات التحليل الركاني للى الطلاب الموهوبين بالمستوى الثالث الثانوي في مدينة مكة المكرمة. 5- لا توجد علاقة ارتباطية ذات دلالة إحصائية عند مستوى (a<0.05) بين مقدار النمو في مفاهيم الأنماط والعلاقات الجغرافية ومهارات التحليل المكاني لدى الطلاب الموهوبين بالمستوى الثالث الثانوي في مدينة مكة المكرمة. 6- لا توجد علاقة اعتمادية تتبؤيه ذات دلالة إحصائية عند مستوى الدلالة (as0.05) بدرجات الطلاب لمجموعة الدراسة في مهارات التحليل المكاني من درجاتهم في اختبار التحصيل المعرفي لمفاهيم الأنماط والعلاقات الجغرافية.

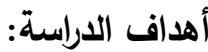
سعت الدراسة الحالية إلى تحقيق الأهداف الآتية: 
1- إعداد قائمة بمفاهيم الأنماط والعلاقات الجغرافية، ومهارات التحليل المكاني التي ينبغي تضمينها في منهج الجغرافيا لاى الطلاب الموهوبين بالمرحلة الثانوية. 2- بناء البرنامج التعليمي المقترح القائم على الخرائط الرقمية، وكذلك بناء أداتي جمع البيانات، وهما: اختبار التحصيل المعرفي وفق مستويات بلوم الدنيا والعليا لقياس مفاهيم الأنماط والعلاقات الجغرافية، وبطاقة الملاحظة الصفية لمهارات التحليل المكاني لاى الطلاب الموهوبين بالمستوى الثالث الثانوي. وإجراء قيم الصدق والثبات اللازمة للأداتين. 3- قياس فاعلية البرنامج التعليمي المقترح القائم على الخرائط الرقية في تتمية مفاهيم الأنماط والعلاقات الجغرافية لدى الطلاب الموهوبين بالمستوى الثالث الثانوي. 4- قياس فاعلية البرنامج التعليمي المقترح القائم على الخرائط الرقمية في تتمية مهارات التحليل المكاني لدى الطلاب الموهوبين

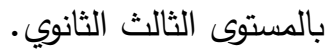
5- قياس العلاقات الارتباطية والاعتمادية التتبؤية بين مقدار النمو في مفاهيم الأنماط والعلاقات الجغرافية ومهارات التحليل المكاني لدى الطلاب الموهوبين بالمستوى الثالث الثانوي. أهمية الدراسة نبعت أهمية هذه الدراسة من استخدام الخرائط الرقمية في الكثير من مجالات الحياة المعاصرة، فقد أضحت الخرائط الرقمية أحد الاتجاهات الحديثة التي تحظى باهتمام بالغ في مجال تدريس التطبيقات المكانية. ويعزى هذا الاهتمام إلى المخرجات التعليمية الايجابية من تدريس الخرائط الرقمية، ومنها مساعدة طلبة المرحلة الثانوية بصورة عامة والطلبة الموهوبين بصورة خاصة على تتمية مفاهيم الأنماط والعلاقات الجغرافية ومهارات التحليل المكاني، والتي تسهم بدورها في اتخاذ قرارات صائبة لها علاقة وطيدة ومهمة بحياة الإنسان. علاوة على إمدادهم بالأدوات والتطبيقات الصحيحة والضرورية لاستخدام الخرائط الرقمية. إضافة إلى ذلك؛ تعد هذه الدراسة بمثابة محاولة جادة لمواكبة الاتجاهات الحديثة في الاهتمام بالتطبيقات الجغرافية التربوية لاستخدام الخرائط الرقمية. الأمر الذي يؤمل منه المساهمة في إثراء الأدب التربوي المتعلق بتوظيف التقنيات الجغرافية في تزويد الطلبة بالمعارف والمهارات الجغرافية الحديثة. محددات الدراسة - المحددات الموضوعية: اقتصرت الدراسة الحالية على قياس فاعلية البرنامج التعليمي المقترح القائم على الخرائط الرقمية في تتمية مفاهيم الأنماط والعلاقات الجغرافية ومهارات التحليل المكاني.

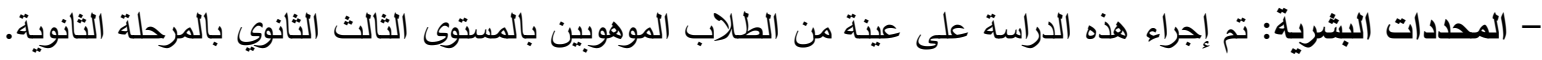
- المحدات المكانية: طُبقت هذه الدراسة في مدرسة بكة الثانوية الحكومية للبنين المخصصة للطئة للطلاب الموهوبين في تعليم مدينة مكة المكرمة. - المحددات الزمانية: تم تطبيق هذه الدراسة -بحمد الله- في الفصل الدراسي الأول للعام الدراسي 1441هـ (2019م). مصطحات الدراسة الفاعلية: عرفها العميري (234،2014) بأنها:"الأثر الحقيقي الناجم عن المتغير المستقل على المتغير التابع، والذي يقاس بمعامل بلاك للفاعلية". 
ويعرفها الباحثان إجرائيا بأنها: قدرة البرنامج التعليمي المقترح في الجغرافيا القائم على الخرائط الرقمية في تتمية المتغيرين

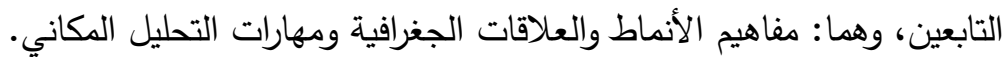

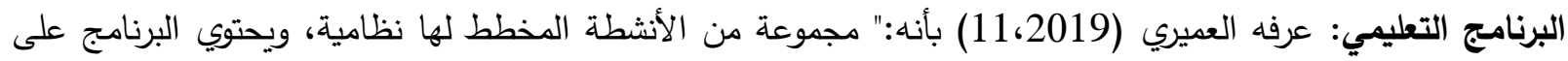
مجموعة من الأهداف والمحتوى والأنشطة والوسائل، وأدوات التقويم". ويمكن تعريف البرنامج التعليمي إجرائياً: مجموعة التئة التئة مترابطة من الموضوعات الجغرافية القائمة على الخرائط الرقمية، والتي يُراد تقديمها للطلبة الموهوبين بالمستوى الثالث الثانوي في صورة خبرات متكاملة ومنظمة. الجغرافيـا: عرفها الوليعي (2018،11) بأنها:" العلم الذي يدرس سطح الأرض ماعليها من الظواهر الطبيعيـة والبشرية وماينتج عنها من علاقات وتفاعلات". الخرائط الرقمية:" تثكيل المعالم الخرائطية بشكل تتيح حفظ العناصر الرقمية ومعالجتها، وعرضها، وطباعتها بإستخدام نظم

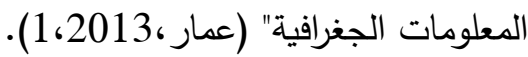
ويعرفها الباحثان إجرائيا بأنها: عبارة عن التمثيل الرقمي لسطح الأرض أوجزءً منها بحيث يتم استخدامه في تتمية مفاهيم الأنماط والعلاقات الجغرافية ومهارات التحليل المكاني في مقرر الجغرافيا لدى الطلاب الموهوبين بالمستوى الثالث الثانوي.

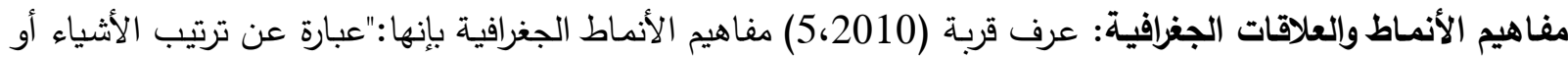

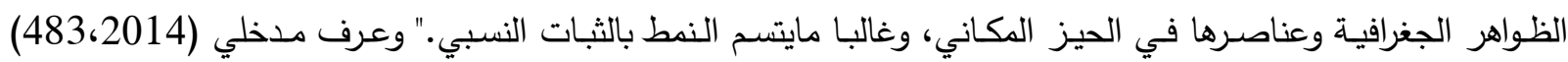
العلاقات الجغرافية بإنها: "البحث عن التفاعلات والعلاقات بين الظواهر الجغرافية وعناصرها في الحيز المكاني التي توجد فيه". ويقصد في هذه الدراسة بمفاهيم الإنماط والعلاقات الجغرافية هي تلك المفاهيم الجغرافية التي تم التوصل إليها من

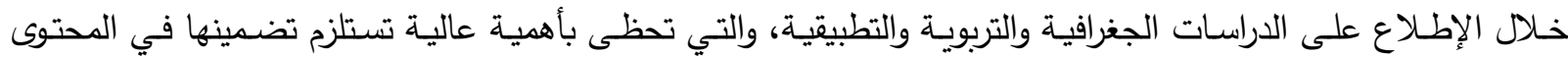
المعرفي لمقررات الجغرافيا بالمرحلة الثانوية للطلبة الموهوبين. مهارات التحليل المكاني: يعرفها البناي (2016،10) بأنها:" تطبيق عملي لمنهج الجغرافيا الحديث القائي على التهائ التحليل بدراسة المكان والعلاقات وبتحويل البيانات إلى معلومات لاستخدامها فيث اتخاذ القرار الأفضل". ويعرفها الباحثان إجرائيا: بإنها القدرة على تتمية مهارات التحليل المكاني المعتمدة على الخرائط الرقمية بدقة واتقان. الطلاب الموهوبين بالمستوى الثالث الثانوي: يقصد بهم الطلاب الموهوبين أصحاب القدرات العقلية العالية الذين اجتازوا

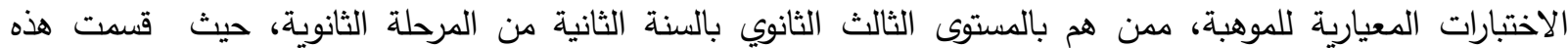

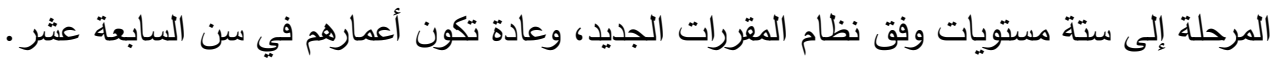
منهجية الدراسة وإجراء اتها

مجتمع الدراسة وعينتها: اشتمل مجتمع الدراسة على جميع الطلاب الموهوبين في المدارس الثانوية الحكومية للبنين في المملكة العربية السعودية. وتمثلت عينة الدراسة في الطلاب الموهوبين بالمستوى الثالث من إحدى الثانويات الحكومية للبنين في مدينة مكة المكرمة، وتم اختيار العينة بطريقة العينة العشوائية المتيسرة. منهج الدراسة: اتبعت الدراسة المنهج شبه التجريبي - ذو تصميم المجموعة الواحدة لكونه المنهج الملائم لطبيعية هذه

بناء البرنامج التعليمي القائم على نظم الخرائط الرقمية بعد الاطلاع على الأدب التربوي وعلى الدراسات السابقة التي هدفت إلى تصميم وبناء البرامج التعليمية والتدريبية المقترحة كدراسة (العميري،2014؛ صالح،2017؛ أبو سالم والأغا،2018). فقد تم تصميم البرنامج التعليمي القائم على الخرائط الرقمية كبرنامج جوجل إيرث (Google Earth)، وخرئط جوجل مابس (Googie Map) في (15) موضوعاً، ترتبط بمفاهيم الأنماط والعلاقات الجغرافية، ومهارات التحليل المكاني. 1- الأسس التي قام عليها البرنامج التعليمي: أ- تحديد أهداف البرنامج التعليمي، وصياغته في عبارات إجرائية واضحة. ب- ارتباط الموضوعات بأهداف البرنامج التعليمي. 
ج- ملائمة موضوعات البرنامج التعليمي للطلبة الموهوبين بالمرحلة الثانوية. د - ربط موضوعات البرنامج التعليمي بالتقنيات والوسائل التعليمية الحديثة، والأنشطة التعلئية التعية.

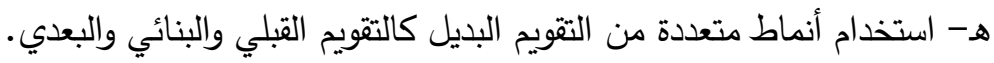

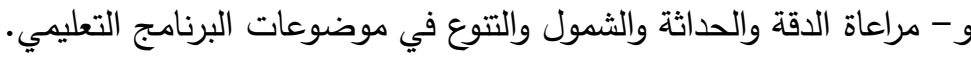

2- 2 - 2 أهداف البرنامج التعليمي أ- التعرف إلى مفهوم الخرائط الرقمية. ب- تحديد أهداف الخرائط الرقمية. ج- ذكر أنماط مفاهيم الأنماط والعلاقات الجغرافية. د- تعليل أهمية الخرائط الرقمية. هـ - استخدام أهم برامج الحاسوب في تصميم الخرائط الرقمية.

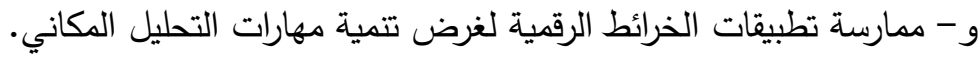

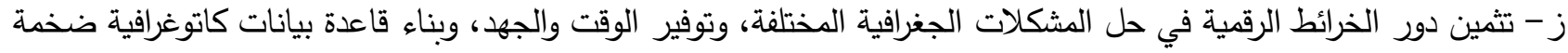
للظواهر الجغرافية الطبيعية والبشرية. ط- تحليل الخرائط الرقمية لبعض الظواهر الجغرافية الطبيعية والبشرية المحلية. أ- مراعاة التنظيم السيكلوجي والمنطقي. ب- الاتصاف بالعمق والاتساع، بما يتتاسب مع مستئ مستوى الطلبة. ج- استخدام الاستراتيجيات والنماذج البنائية في التدريس. د- توظيف التقنيات والوسائل التعليمية الحديثة. هـ - احتوائها على الأنثطة التعلمية المطلوبة من الطلاب، مع إيضاتح كيفية القيام بها، ودرجة تكرارها، ومستوى الأداء فيها.

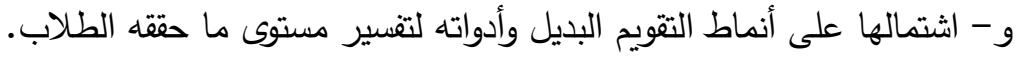

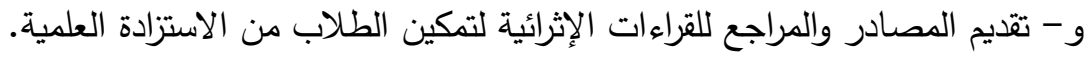

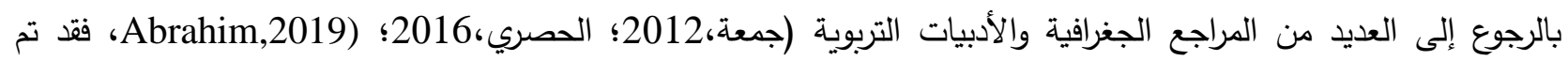

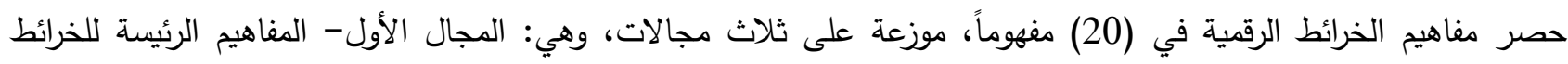

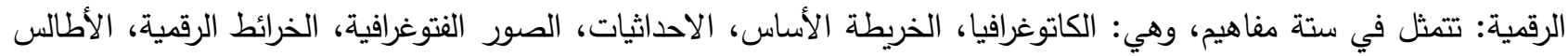

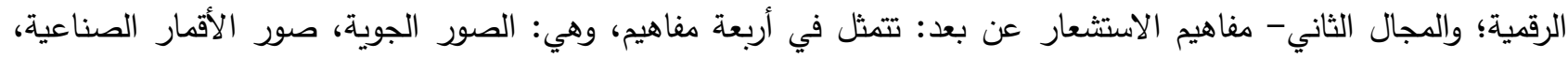

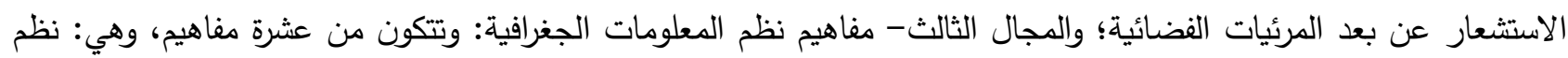

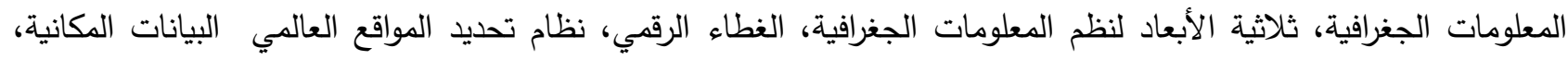
البيانات الوصفية، برنامج جوجل الأرض، برنامج جوجل مابس، برنامج خرائط واز ، الخرائط الذبة الذكية.

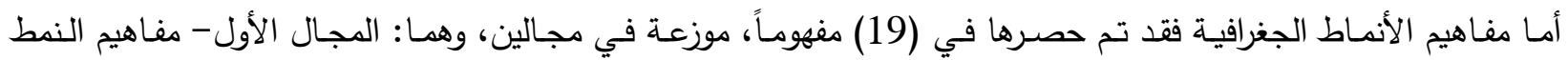

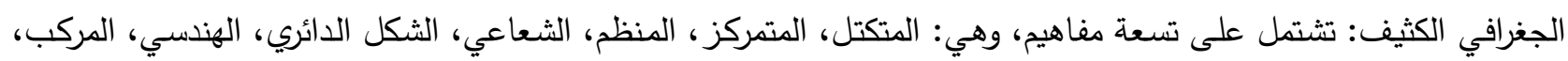

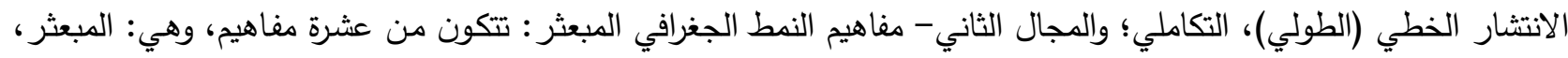

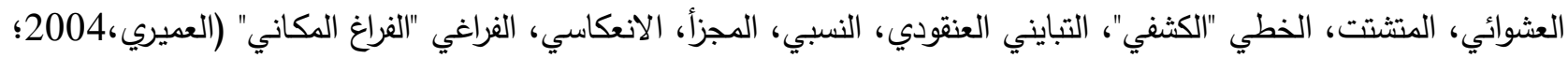

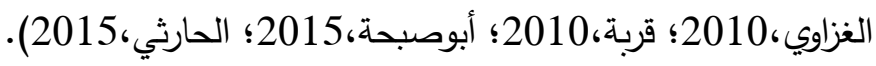

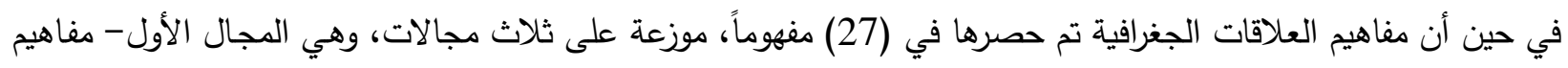
العلاقات الجغرافية الطبيعية: تتكون من ستة مفاهيم، وهي: السببية ، التراكمية، التتابعية، التسلسلية، التكاملية، الجزئية؛ المجال الثاني- مفاهيم العلاقات الجغرافية المتعلقة بالاتجاهات: تتمثل في سبعة مناهيته مفاهيم، وهي: الطردية، العكسية، الجهوية، التصنيفية، 
اللا ارتباطية، الحجية، الثكلية؛ والمجال الثالث- مفاهيم العلاقات الجغرافية المتصلة بوصف التقارب بين الأماكن: تتضمن

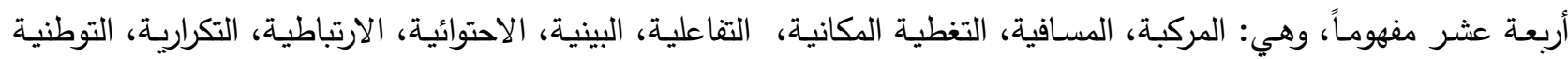

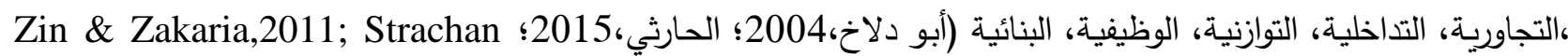

.(\&Mitchell, 2014.

أما مهارات التحليل المكاني فقد تم حصرها في (22) مهارة، مقسمة على مجالين، وهما: المجال الأول - مهارات العمل الحقلي

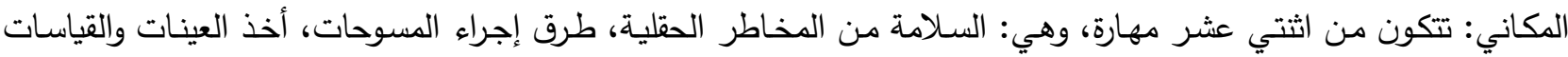

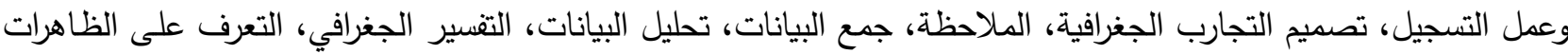
الدكانيـة، التكامل، التواصل وقابليـة التحويل، حل المشكلات؛ والمجـال الثانيـ- المهارات الكاتوغرافيـة المكانيـة المعتمدة على التقنيات الجغرافيـة: تشتـمل على عشرة مهارات، وهي: القراءة للظـاهرات المكانيـة، معالجـة بيانـات الظـاهرات المكانيـة، تفسير

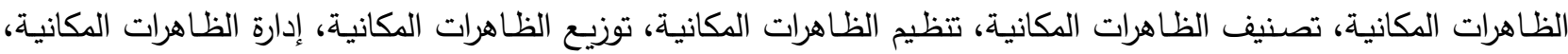
استخلاص الظـاهرات المكانية، التخيل (التتبؤ) بالتغير للظاهرات المكانيـة، صنع واتخـاذ القرار للظاهرات المكانية (الآغا وأبو

سالم، 2018؛ Almairi,2019).

4- أدريس البرنامج التعليمي أ- استراتيجيات التدريس البنائي ونماذجه: تتمثل في استراتيجة الاستكثاف، واستراتيجية الاستقصاء، واستراتجية حل المشكلات إبداعياً، ونموذج التعلم التعاوني، ونموذج التعلم التوليدي. ب- التقنيات والوسائل التعليمية الحليثة: تم توظيف برامج العروض التقديمية (Keynote, Power Point, Prezi) لعرض المحتوى التعليمي المرتبط بنظم المعلومات الجغرافية، والسبورة الذكية، والأطالس الرقمية، والصور الفتوغرافية، والصور الجوية، ومرئيات الاستثعار عن بعد.

ج- الأنشطة التعلمية: يكمن دور الأنشطة التعمية في التطبيقات العملية من خلال اتاحة الفرصة للطبلة الموهوبين لممارسة مهارات التعلم، وتثكيل خبرات الطلبة، ومن أهمها: الاستتتاج والاستكثاف والمقارنة والتحليل. د- القراءات الخارجية: اشتملت على الكتب المتخصصة، والدراسات المنشورة في المجلات العلمية، والمؤتمرات البحثية، والمدونات على الثبكة المعلوماتية. 5- أنماط التقويم وأدواته: تم استخدام نمطين من التقويم، وهما: أ- التقويم العام: تم إجراءه قبل وبعد تدريس البرنامج التعليمي (التقويم القبلي، والتقويم البعدي)، حيث تم تطبيق أداتي الدراسة. ب- التقويم أثناء التدريس: استخدمت ثلاثة أنماط من التقويم للوحدة التعليمية، وهي: التقويم القبلي من خلال طرح أسئلة في بداية الحصة الدراسية. والتقويم البنائي من خلال تدريس الوحدات، وذلك عن طرق الأسئلة المباشرة للكثف عن مستوى تحقق الأهداف التعليمية والتقويم الختامي في نهاية كل موضوع للتأكد من تحقيق الأهداف التعليمية.

أداتا الدراسة أولاً- اختبار التحصيل المعرفي 1- بناء الاختبار: تم بناء اختبار التحصيل المعرفي وفقاً لتصنيف بلوم في مستوياته الستة، وهي: التذكر، الفهم والاستيعاب، التطبيق، التحليل، التقويم. وذلك لقياس درجة تحصيل طلاب المستوى الثالث الثانوي لمفاهيم الأنماط والعلاقات الجغرافية. وتم صياغة أسئلة اختبار التحصيل المعرفي لمفاهيم الأنماط والعلاقات الجغرافية في (50) سؤالًا موضوعياً. واستخدمت ثلاثة أنماط 
من الأسئلة الموضوعية، وهي: أسئلة الصواب والخطأ، وتمثلت في (10) فقرات، منها (6) فقرات صحيحة، و(4) فقرات خاطئة. وجاء السؤال الثاني من أسئلة الاختيار من متعدد ذو البدائل الأربعة، أحداهما فقط صحيح، واشتملت على (30) فقرة. وتتاول السؤال الثالث أسئلة المزاوجة، وتكونت من(10) فقرات، يقابها (12) فقرة، اثتان منهما ليست من ضمن الإجابات الصحيحة.

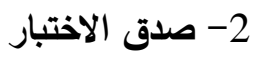
أ- الصدق الظاهري للاختبار: عُرض الاختبار على مجموعة من المحكمين وصل عددهم إلى (15) من ذوي الاختصاص في الجغرافيا، والمناهج وطرق التدريس، والجغرافيا التربوية، والذين قاموا بإبداء بعض الملاحظات، كما قدما بعض المقترحات على فقرات الاختبار • وقد تم اعتماد نسبة اتفاق (80\%) من مجموع المحكمين (صوان،2017). أي بواقع اتفاق (12) محكماً لاعتماد التعديل والحذف والإضافة، وظهر الاختبار في نسخته النهائية في (50) سؤلاً. ب- الصدق البنائي للاختبار: طُبقت التجبة الاستطلاعية للاختبار على (10) من الطلاب الموهوبين من خارج العينة، بهدف حساب معامل السهولة والصعوبة لأسئلة الاختبار، ووجد أن معاملات السهولة تراوحت ما بين (0,21- 0,28)، في حين تراوحت معاملات الصعوبة بين (0,71 -0,87). مما يعني أن جميع فقرات الاختبار تقع داخل النطاق المحدد لمعاملات السهولة والصعوبة (أبو علام، 2018). تلى ذلك تم حساب تباين أسئلة الاختبار لمعرفة القدرة التميزية لكل سؤال، واتضح أن جميع الأسئلة تراوحت بين (0,85-0,28)، وأيضاً تقع ضمن النطاق المحدد. وقد تبين من خلال التجربة الاستطلاعية أن متوسط الزمن المناسب لإنهاء جميع الطلاب الموهوبين الإجابة عن جميع فقرات الاختبار هو (50) دقيقة. وتم تقدير درجات الاختبار بواقع (درجة واحدة) لكل سؤال. كما تم كتابة التعليمات الخاصة بالاختبار ، وكيفية الإجابة عنها في نموذج الإجابة المعد لهذا الغرض. إضافة إلى ذلك؛ تم حساب معاملات ارتباط بيرسون بين درجة كل سؤال والدرجة الكلية، وذلك لتوضيح قوة الارتباط بين درجات كل سؤال مع الدرجة الكلية للاختبار الذي تتتمي إليه، وقد بلغ معامل الأسئلة مع الدرجة الكلية (0,875)، وتعتبر هذه القيمة مرتفعة، وهي دالة إحصائياً عند مستوى (as0.01). .Choen Mannion \& Morrisonn, 2011). 2- ثبات الاختبار: تم التأكد من ثبات الاختبار باستخدام معادلة كودر ريتشاردسون 20 (R-20)، لكونها الأكثر شيوعاً في حساب ثبات الاختبارات التي يعطي فيها درجة واحدة للإجابات الصحيحة، وصفر للإجابة الخاطئة، وبلغت قيمة معامل ثبات الاختبار (0,72)، وهذا يدل على أن الاختبار على درجة عالية من الثبات والتجانس (مجيد، 2014). ثانياً- بطاقة الملاحظة الصفية 1- بناء بطاقة الملاحظة الصفية: هدفت هذه البطاقة إلى قياس مهارات التحليل المكاني لدى الطلاب الموهوبين قبل تطبيق البرنامج التعليمي وبعده. وتم الاطلاع على عدد من المقاييس التي صُممت لقياس المهارات الجغرافية بشكل عام ومقاييس مهارات التحليل المكاني بصفة خاصة، كدراسة(عبد الحكيم،2016؛الحربي والأنصاري،2019 Carbonell \& Hess,2019). واستخدم المقياس الثلاثي لتقدير درجة استجابات العينة على فقرات البطاقة، وهي: مرتفعة، متوسطة، منخفضة. حيث أعطيت المرتفعة (3) درجات، والمتوسطة (2) درجتان، والمنخفضة (1) درجة واحدة. وتمثلت مجالات بطاقة الملاحظة الصفية لمهارات التحليل المكاني في مجالين. وتم التأكد من استيفاء الاعتبارات الهامة التي يجب مراعاتها عند صياغة فقرات بطاقة الملاحظة، كما تم كتابة التعليمات الخاصة بالبطاقة. 
أ- الصدق الظاهري: عُرضت بطاقة الملاحظة في نسختها الأولية على مجموعة من المحكمين مكونة من (15) محكماً من ذوي الاختصاص في الجغرافيا، ومناهج وطرق تدريس الجغرافيا، وتقنيات التعليم. وذلك للتأكد من مستوى انتماء الفقرات لأغراض البطاقة، وفي ضوء اقتراحاتهم تم إجراء بعض التعديلات الضرورية. وتكونت بطاقة الملاحظة لمهارات التحليل المكاني في نسختها النهائية من مجالين، ومجموع فقراتها (22) فقرة، موزعة على مجالين. ب- الصدق البنائي: تم تطبيق البطاقة على عينة استطلاعية مكونة من (10) طلاب، من خارج عينة الدراسة، ومن ثم استخراج معاملات صدق الاتساق الداخلي، وبحساب معامل ارتباط بيرسون (Person Correlation) بين كل فقرة من الفقرات مع الدرجة الكلية للبطاقة بقصد إظهار مدى اتساق الفقرات في قياس المجالات الواردة فيها. وقد تراوحت قيم معاملات الارتباط لفقرات البطاقة بين (581 - 928) وبدلالة إحصائية (a<0.01)مما يدل على مناسبة هذه الفقرات لقياس مستوى ممارسة الطلاب الموهوبين لمهارات التحليل المكاني (أبو علام، 2018). وفي ضوء نتيجة الاتساق الداخلي لفقرات بطاقة الملاحظة؛ لم تحذف أي فقرة من فقرات البطاقة، وقد ظهر أن قيم معاملات ارتباط الفقرات ترتبط بالدرجة الكلية للبطاقة ارتباطاً تجاوز (0,80)، ويوصف بالارتباط المرتفع (عودة،2014). وقد رافق هذا الارتباط المرتفع دلالة إحصائية (a>0.01)، مما يؤكد أن بطاقة الملاحظة تتمتع بدرجة عالية من الصدق البنائي. 3- ثبات بطاقة الملاحظة: تم حساب ثبات بطاقة الملاحظة عن طريق معامل الاتفاق، حيث طبقت بطاقة الملاحظة على العينة الاستطلاعية المكونة من (10) طلاب، لحساب عدد مرات الاتفاق والاختلاف، بغية التأكد من إعطائها نتائج مشابهة في حال استخدامها مرة أخرى. وباستخدام معادلة كوبر (Cooper Equation)، وهي:

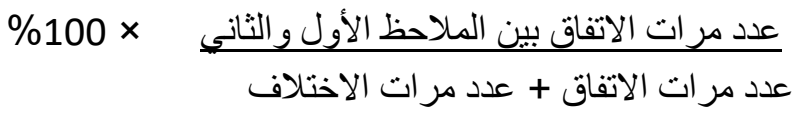
وفي ضوء هذه الخطوات؛ تم حساب ثبات بطاقة الملاحظة، وبعد رصد التقديرات الكمية لحساب مدى الاتفاق والاختلاف بين الملاحظين، فقد تجاوزت قيم معامل الاتفاق بين الملاحظين (80\%) (الريماوي،2017). وهذا يُعد مؤشراً لثبات عملية الملاحظة. وبحساب المتوسط الحسابي لنسب الاتفاق بين الملاحظين، وجد أنه يساوي (92\%)، مما يدل على أن البطاقة تتمتع بدرجة عالية

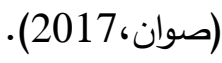
الأساليب الإحصائية المستخدمة في تحليل البيانات استخدمت مجموعة من أساليب الإحصاء الوصفي، وهي: التكرارات، والنسب المئوية، والمتوسطات الحسابية، والانحرافات المعيارية، والخطأ المعياري، والتجانس. كما استخدمت مجموعة من أساليب الإحصاء الاستدلالي، وهي: معامل اعتدالية التوزيع، ومعامل ارتباط بيرسون لقياس الصدق البنائي لأداتي جمع البيانات. ولقياس العلاقة الارتباطية بن المتغيرين المعتمدين، ومعادلة كيودر ريتثاردسون لقياس ثبات اختبار التحصيل المعرفي، ومعادلة كوبر لقياس ثبات بطاقة الملاحظة الصفية، وفحص ويككلسون ، للعينات المترابطة، ومعامل مربع إيتا (لقياس حجم التأثير، ومعامل بلاك للكسب المعدل لقياس الفاعلية، ومعامل بيتا لقياس العلاقة الاعتمادية التتبؤية الخطية. 


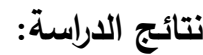

الإجابة عن السؤال الأول

ما فاعلية البرنامج التعليمي المقترح القائم على الخرائط الرقمية في تتمية مفاهيم الأنماط والعلاقات الجغرافية لاى طلاب الموهوبين بالمستوى الثالث الثانوي في مدينة مكة المكرمة؟ الفرضية الأولى لا توجد فروق ذات دلالة إحصائية عند مستوى الدلالة (a<0.05) بين متوسطي رتب مجموعة الدراسة في التطبيقين القبلي والبعدي لاختبار التحصيل المعرفي لمفاهيم الأنماط والعلاقات الجغرافية لدى الطلاب الموهوبين بالمستوى الثالث الثانوي في مدينة

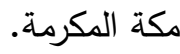

جدول (1) فحص ويلككسون لالالة الفروق بين متوسطي رتب درجات مجموعة الدراسة في التطبيقين القبلي والبعدي في اختبار التحصيل المعرفي لمفاهيم الأنماط والعلاقات الجغرافية لاى الطلاب الموهوبين بالمستوى الثالث الثانوي في مدينة مكة المكرمة

\begin{tabular}{|c|c|c|c|c|c|c|}
\hline مستوى الدلالة & $\begin{array}{c}\text { قيمة زد } \\
\text { (Z) }\end{array}$ & مجموع الرتب & متوسط الرتب & العينة & التطبيق & المعتوفي \\
\hline \multirow{2}{*}{0,003} & \multirow{2}{*}{3,63} & 0,00 & 0,02 & 19 & القبلي & \multirow{2}{*}{ التذكر } \\
\hline & & 153 & 9 & 19 & البعدي & \\
\hline \multirow{2}{*}{0,001} & \multirow{2}{*}{3,82} & 0,00 & 0,01 & 19 & القبلي & \multirow{2}{*}{ والاستيعاب } \\
\hline & & 190 & 10 & 19 & البعدي & \\
\hline \multirow{2}{*}{0,002} & \multirow{2}{*}{3,94} & 0,00 & 0,03 & 19 & القبلي & \multirow{2}{*}{ التطبيق } \\
\hline & & 171 & 9,5 & 19 & البعدي & \\
\hline \multirow{2}{*}{0,004} & \multirow{2}{*}{2,87} & 1 & 1 & 19 & القبلي & \multirow{2}{*}{ التحليل } \\
\hline & & 65 & 6,5 & 19 & البعدي & \\
\hline \multirow{2}{*}{0,001} & \multirow{2}{*}{3,30} & 0,00 & 0,01 & 19 & القبلي & \multirow{2}{*}{ التركيب } \\
\hline & & 105 & 7,5 & 19 & البعدي & \\
\hline \multirow{2}{*}{0,0003} & \multirow{2}{*}{3,00} & 0,00 & 0,02 & 19 & القبلي & \multirow[b]{2}{*}{ التقويم } \\
\hline & & 45 & 5 & 19 & البعدي & \\
\hline \multirow{2}{*}{0,001} & \multirow{2}{*}{3,82} & 0,00 & 0,01 & 19 & القبلي & \multirow{2}{*}{ الدرجة الكلية } \\
\hline & & 190 & 10 & 19 & البعدي & \\
\hline
\end{tabular}

يظهر الجدول (1) أن قيمة متوسط الرتب في مستويات بلوم المعرفية في اختبار مفاهيم الأنماط والعلاقات الجغرافية للدرجة الكلية، ومستوى الفهم والاستيعاب بلغت (10) مقارنة بالدرجة القبلي التي بلغت (0,01)، في حين جاء مستوى التطبيق بقيمة

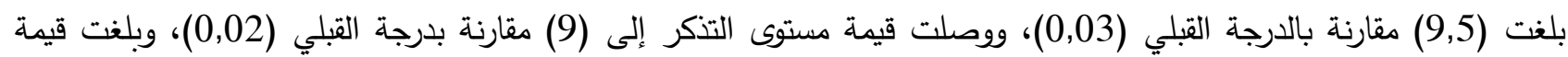

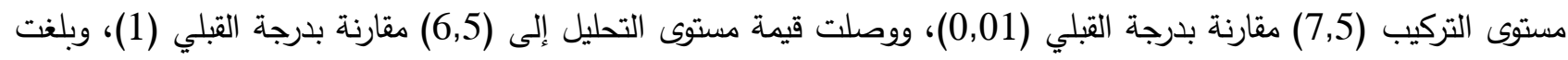

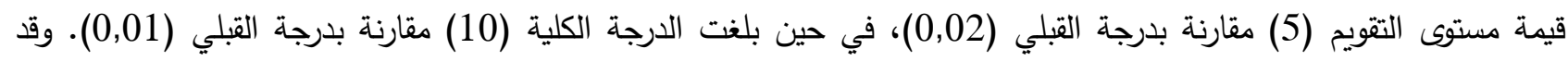
تراوحت قيمة (z) بين (3,94-3)، وبلغت قمية (z) للارجة الكلية في اختبار التحصيل المعرفي (3,82). وجميعها مصحوبة بدلالة إحصائية (a=0.01). وتدل هذه النتائج على أن البرنامج التعليمي المقترح القائم على الخرائط الرقمية له تأثير إيجابي في تتمية مفاهيم الأنماط والعلاقات الجغرافية لدى الطلاب الموهوبين بالمستوى الثالث الثانوي في مدينة مكة المكرمة. 
وتتقق هذه النتيجة للدراسة الحالية مع مجموعة من نتائج الدراسات السابقة في وجود فرق بين التطبيقين القبلي والبعدي لمستويات بلوم المعرفية مصحوباً بدلالة إحصائية (a=0.01)في استخدام البرامج التعليمية المقترحة القائمة على الخرائط الرقمية كدراسة

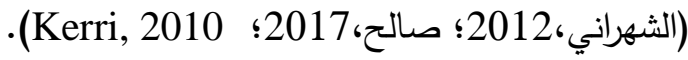
وهذا يقود إلى رفض الفرضية الصفرية الأولى، وقبول الفرضية البديلة الموجهة الأولى التي تتص على: توجد فروق ذات دلالة إحصائية عند مستوى الدلالة (a=0.01)بين متوسطي رتب مجموعة الدراسة في التطبيقين القبلي والبعدي لاختبار التحصيل المعرفي لدفاهيم الأنماط والعلاقات الجغرافية لدى الطلاب الموهوبين بالمستوى الثالث الثانوي في مدينة مكة المكرمة. جدول (2) حجم تأثير البرنامج التعليمي المقترح القائم على الخرائط الرقمية في تنمية مفاهيم الأنماطوالعلاقات الجغرافية لاى الطلاب الموهوبين

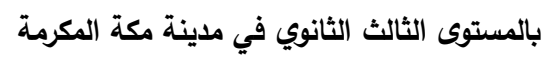

\begin{tabular}{|c|c|c|c|c|}
\hline دلالة حجم التأثير & حجم التأثير & $\begin{array}{c}\text { قيمة زد } \\
\text { (z) }\end{array}$ & العينة & المعرفتوى \\
\hline مرتفع & 0,83 & 3,63 & 19 & التذكر \\
\hline مرتفع & 0,88 & 3,82 & 19 & الفهم والاستيعاب \\
\hline مرتفع & 0,90 & 3,94 & 19 & التطبيق \\
\hline متوسط & 0,66 & 2,87 & 19 & التحليل \\
\hline متوسط & 0,76 & 3,30 & 19 & التركيب \\
\hline متوسط & 0,69 & 3,00 & 19 & التقويم \\
\hline مرتفع & 0,88 & 3,82 & 19 & الارجة الكلية \\
\hline
\end{tabular}

يوضح الجدول (2) أن قيمة حجم التأثير الذي أحدثه البرنامج التعليمي المقترح القائم على الخرائط الرقمية في تتمية التحصيل المعرفي لمفاهيم الأنماط والعلاقات الجغرافية لدى الطلاب الموهوبين في مستوى التطبيق وصلت إلى (0,90)، وفي مستوى الفهم والاستيعاب بلغت (0,88)، وفي مستوى التنكر بلغت (0,83). وجميعها في مستوى حجم التأثير المرتفع حسب تصنيف كوهين

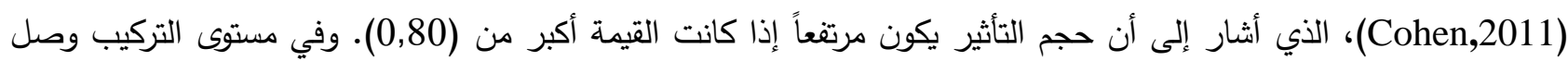
إلى (0,76)، وفي مستوى التقويم بلغ (0,69)، وفي مستوى التحليل وصل (0,66)، وهذه القيم في مستوى حجم التأثير المتوسط ديط حسب تصنيف (Cohen,2011) لأنها أقل من (0,80) وأكثر من (0,50). وبلغت قيمة حجم التأثير عند الدرجة الكلية للاختبار (0,88)، وهي في مستوى حجم التأثير المرتفع حسب تصنيف كوهين. وتدعم هذه النتيجة للدراسة الحالية لحجم التأثير دراسات سابقة قامت على لـى الخرائط الرقمية كمتغير مستقل مع اختلاف المتغيرات التابعة كدراسة (الحصري،:Strachan \&Mitchell, 2014)، ومن جانب آخر ؛ لم تُوجد دراسة سابقة -على حد اطلاع الباحثان - اختلفت مع نتيجة الدراسة الحالية من حيث حجم التأثير . الفرضية الثانية: لا توجد فاعلية للبرنامج التعليمي المقترح القائم على الخرائط الرقميـة في تتميـة التحصيل المعرفي لمفاهيم الأنماط والعلاقات الجغرافية لدى الطلاب الموهوبين بالمستوى الثالث الثانوي في مدينة مكة المكرمة. جدول (3): نسبة الكسب المعدل لبلاك لقياس فاعلية الخرائط الرقمية في تنمية التحصيل المعرفي لمفاهيم الأنماط والعلاقات الجغرافية لاى الطلاب الموهوبين بالمستوى الثالث الثانوي في مدينة مكة المكرمة 


\begin{tabular}{|c|c|c|c|c|}
\hline المعدل لبلاك الكسب & متوسط درجة اختبار & متوسط درجة اختبار & الأسئلة & المستوفي \\
\hline 1,24 & 12,74 & 6,8 & 14 & التذكر \\
\hline 1,21 & 17,5 & 8,8 & 20 & الفهم والاستيعاب \\
\hline 1,23 & 3,74 & 2,2 & 4 & التطبيق \\
\hline 1,22 & 4,30 & 2,00 & 5 & التحليل \\
\hline 1,26 & 5,58 & 3,11 & 6 & التركيب \\
\hline 1,38 & 0,95 & 0,47 & 1 & التقويم \\
\hline 1,23 & 44,81 & 23,38 & 50 & مجموع الأسئلة \\
\hline
\end{tabular}

يبين الجدول (3) أن نسبة معدل الكسب لبلاك (Blake) للدرجة الكلية لاختبار التحصيل المعرفي لمفاهيم الأنماط والعلاقات الجغرافية بلغت (1,23\%). وجاءت نسبة معدل الكسب لبلاك لمستوى التقويم في الترتيب الأول، حيث بلغت النسبة (1,38\%).

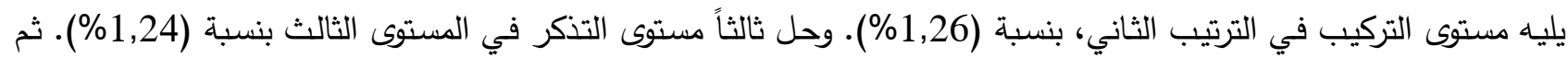
مستوى التطبيق في المستوى الرابع، بنسبة (1,23\%). يليه مستوى التحليل في المستوى الخامس، بنسبة (1,22\%). (أخيراً) مستوى الفهم والاستيعاب، بنسبة (1,21\%). وجميع هذه القيم أكبر من (1,20 \%)، حيث إنها القيمة الدحك التي حددها بلاك (Blake) المشار إليه في العميري (2019،27) لتحديد الفاعلية. مما يؤكد أن البرنامج التعليمي المقترح القائم على الخرائط الرقمية ذو فاعلية عالية. ويمكن تفسير فاعلية البرنامج التعليمي المقترح القائم على الخرائط الرقمية ساهم بدور فاعل وجوهري في تتمية التحصيل المعرفي لمفاهيم الأنماط والعلاقات الجغرافية في أن الخرائط الرقمية أوضحت وفسرت الأنماط والعلاقات الجغرافية باستخدام صور الأقمار الصناعية (Satellite Images، وجوجل إيرث (Google Earth)، وخرئط جوجل مابس (Googie Map) من خلال العرض التقديمي لموضوعات البرنامج التعليمي، والتي ساهدت في توضيح الحقائق والمفاهيم المتصلة بالأنماط والعلاقات الجغرافية، وجعل عملية التعلم جاذبة وشيقة، بحيث تثير دافعية الطلاب الموهوبين، وتزيد من إقبالهم على التعلم. مما انعكس إيجاباً على تتمية التحصيل المعرفي لديهم. وهذه النتيجة للدراسة الحالية تدعمها ما توصلت إليه نتائج بعض الدراسات السابقة التي تتاولت الأهمية المعرفية والتعليمية لدفاهيم الأنماط والعلاقات الجغرافية كدراسة (الحارثي،2015؛ . Sturz, Kelly \& Brown, 2009). ومن جانب آخر ؛ ساعد الوصول المباشر والمرن إلى المعلومات المرتبطة بموضوعات البرنامج التعليمي المقترح على التقدم في التعلم بالسرعة الخاصة لكل طالب موهوب، مما ساهم في التمكن من الفهم الكامل والعميق لمفاهيم الأنماط والعلاقات الجغرافية. وفي ضوء ذلك؛ تم دحض الفرضية الصفرية الثانية، وقبول الثرضية البديلة الموجهة الثانية التي تتص على أنه: توجد فاعلية للبرنامج التعليمي المقترح القائم على الخرائط الرقمية في تتمية التحصيل المعرفي مفاهيم الأنماط والعلاقات الجغرافية لدى الطلاب الموهوبين بالمستوى الثالث الثانوي في مدينة مكة المكرمة. الإجابة عن السؤال الثاني: مـا فاعلية البرنـامج التعليمي المقترح القائم على الخرائط الرقمية في تتمية مهارات التحليل المكاني للى الطـلاب الموهوبين بالمستوى الثالث الثانوي في مدينة مكة المكرمة؟ 


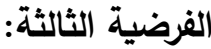

لا توجد فروق ذات دلالة إحصائية عند مستوى الدلالة (as0.05)بين متوسطي رتب مجموعة الدراسة في التطبيقين القبلي والبعدي

لمهارات التحليل المكاني لدى الطلاب الموهوبين بالمستوى الثالث الثانوي في مدينة مكة المكرمة. جدول (4) فحص ويلكسون لالالة الفروق بين متوسطي درجات مجموعة الدراسة في التطبيقين القبلي والبعدي في بطاقة الملاحظة لمهارات التحليل

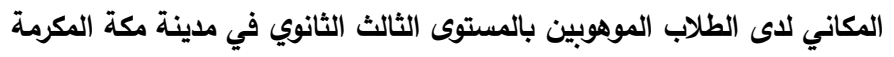

\begin{tabular}{|c|c|c|c|c|c|c|c|}
\hline حجم التأثير & قيمة مستوى الدلالة & قيمة زد & مجموع الرتب & متوسط الرتب & علد & التطبيق & المجال \\
\hline \multirow{2}{*}{0,88} & \multirow{2}{*}{0,003} & \multirow{2}{*}{3,83} & 0,00 & 0,01 & 19 & القبلي & \multirow{2}{*}{ للتحليل المكاني الأساسية } \\
\hline & & & 190,00 & 10,00 & 19 & البعدي & \\
\hline \multirow{2}{*}{0,88} & \multirow{2}{*}{0,002} & \multirow{2}{*}{3,86} & 0,00 & 0,02 & 19 & القبلي & \multirow{2}{*}{ المعتمارة الكاتورغرافية التقنيات } \\
\hline & & & 190,00 & 10,00 & 19 & البعدي & \\
\hline \multirow{2}{*}{0,88} & \multirow{2}{*}{0,001} & \multirow{2}{*}{3,83} & 0,00 & 0,01 & 19 & القبلي & \multirow{2}{*}{ لمهارات التحليل المكاني } \\
\hline & & & 190,00 & 10,00 & 19 & البعدي & \\
\hline
\end{tabular}

يُظهر الجدول (4) أن قيمة متوسط الرتب في مجال المهارات الأساسية للتحليل المكاني وصلت إلى (190) مقارنة بدرجة القبلي

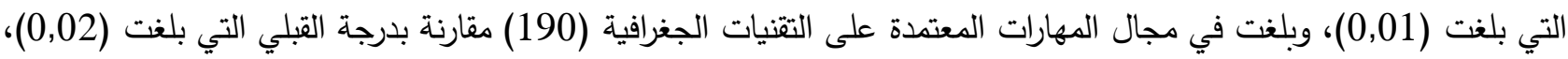
وإجمالاً بلغت الدرجة الكلية (190) مقارنة بدرجة القبلي التي بلغت (0,01). ويكثف الجدول (4) أن قيمة زد (z) في مجال المهارات الأساسية للتحليل المكاني بلغت (3,83)، وفي مجال المهارات الكاتورغرافية المعتمدة على التقنيات الجغرافية بلغت (3,86) عند مستوى الدلالة الاحصائية (a a $)$ (aين متوسطي درجات مجموعة الدراسة في التطبيقين القبلي والبعدي لصالح

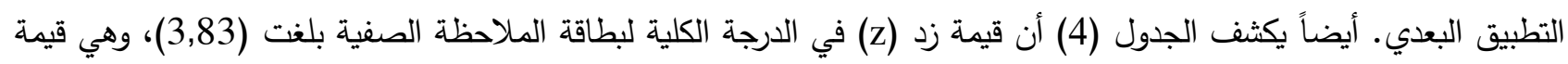
دالة إحصائياً عند مستوى دلالة (as0.01)؛ مما يعني وجود فروق بين متوسطي درجات مجموعة الدراسة في التطبيقين القبلي والبعدي في الدرجة الكلية لمهارات التحليل المكاني. وتعود هذه الفروق لصالح التطبيق البعدي. وتدل هذه النتيجة على أن البرنامج

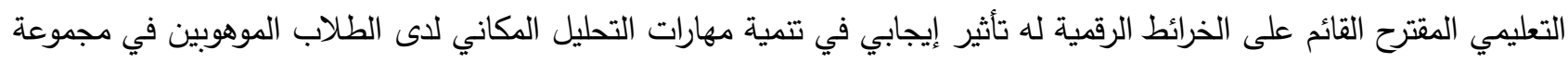
الدراسة. وتتفق هذه النتيجة مع نتائج الدراسات السابقة التي كثفت عن التأثير الإيجابي المرتفع عند استخدام البرامج التعليمية المقترحة القائمة على الخرائط الرقمية في تتمية مهارات التحليل المكاني كدراسة (الآغا وأبو سالم،2018؛ الحربي والأنصاري،

كما أظهرت نتيجة مربع إيتا في الجدول (4) حجم التأثير الإيجابي المرتفع لاستخدام البرنامج التعليمي القائم على الخرائط الرقمية في تتمية مهارات التحليل المكاني، حيث بلغت قيمته (0,88) في كل من مجال المهارات الأساسية للتحليل المكاني، ومجال المهارات الكاتورغرافية المعتدة على التقنيات الجغرافية، والدرجة الكلية لمهارات التحليل المكاني، وهي في مستوى حجم التأثير المرتفع حسب تصنيف كوهين (Cohen,2011). وتتقق هذه النتيجة مع نتائج الدراسات السابقة التي كثفت عن التأثير 
الإيجابي المرتفع عند استخدام البرامج التعليمية المقترحة القائمة على الخرائط الرقمية في تتمية مهارات التحليل المكاني، كدراسة

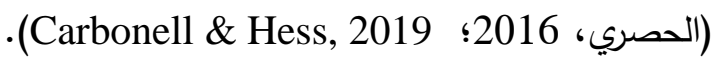
وهذا يقود إلى رفض الفرضية الصفرية الثالثة، وقبول الفرضية البديلة الموجهة الثالثة التي تتص على أنه: توجد فروق ذات دلالة إحصائية عند مستوى الدلالة (a=0.01) بين متوسطي رتب مجموعة الدراسة في التطبيقين القبلي والبعدي لمهارات التحليل المكاني لدى الطلاب الموهوبين بالمستوى الثالث الثانوي في مدينة مكة المكرمة.

الفرضية الرابعة:

لا توجد فاعلية للبرنامج التعليمي المقترح القائم على الخرائط الرقمية في تتمية مهارات التحليل المكاني لدى الطلاب الموهوبين بالمستوى الثالث الثانوي في مدينة مكة المكرمة.

جدول (5) نسبة الكسب المعدل لبلاك لقياس فاعلية الخرائط الرقمية في تنمية مهارات التحليل المكاني لاى الطلاب الموهوبين بالمستوى الثالث الثانوي في مدينة مكة المكرمة

\begin{tabular}{|c|c|c|c|c|}
\hline نسبة الكسب & متوسط درجة بطاقة & متوسط درجة بطاقة & الدارجة الكلية لبطاقة & المجال \\
\hline 1,22 & 31,52 & 15,57 & 36 & المهارات الأساسية \\
\hline 1,23 & 26,26 & 12,73 & 30 & 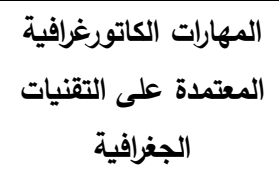 \\
\hline 1,23 & 57,78 & 28,31 & 66 & لمهارات التحليل المكاني \\
\hline
\end{tabular}

يظهر الجدول (5) أن معدل الكسب المعدل لبلاك (Blake) للمهارات الأساسية للتحليل المكاني في بطاقة الملاحظة الصفية

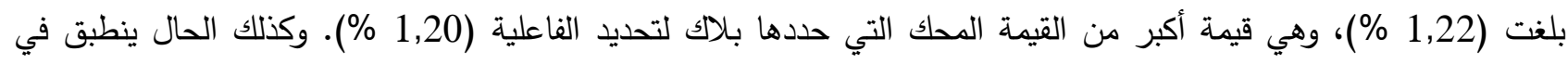

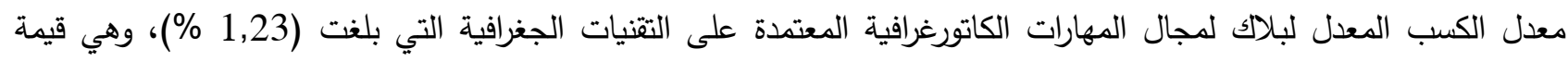

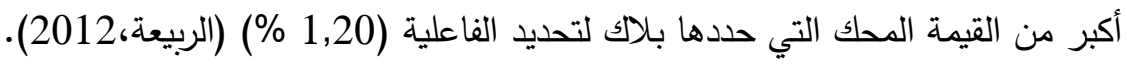
كما يظهر الجدول (5) أن نسبة معدل الكسب لبلاك (Blake) للارجة الكلية لبطاقة الملاحظة الصفية لمهارات التحليل المكاني بلغت (1,23 \%)، وهي قيمة أكبر من القيمة المحك التي حددها بلاك لتحديد الفاعلية (1,20 \% م). مما يشير إلى أن البرنامج أثبت فاعليته.

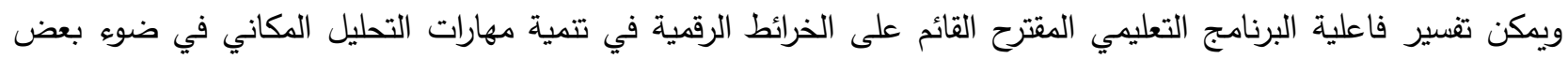

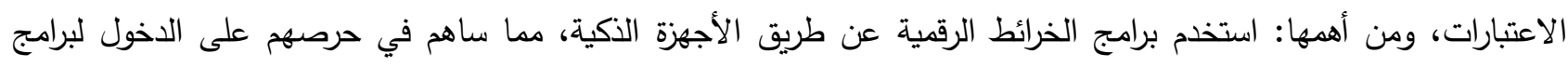
الخرائط الرقمية في أي وقت وفي أي مكان، واتصالهم المستمر والمتفاعل مع تلك البرامج، وبالتالي حصولهم على المهارات المرتبطة بالتحليل المكاني. ومن جانب آخر؛ قدم البرنامج التعليمي المقترح القائم على الخرائط الرقمية فرصاً أمام الطلاب الموهوبين للقيام بمراجعة ما

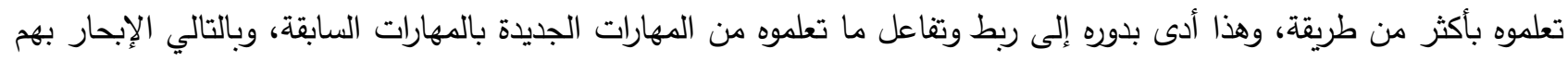
صوب المزيد من الإتقان لمهارات التحليل المكاني، وتأسيساً على ما تقدم؛ فإن هذه النتيجة المتصلة بمهارات التحليل المكاني تؤكد فاعليته، مما يعكس القيمة الكبيرة للبرنامج التعليمي الذي خضع له الطلاب الموهوبين. وتتفق هذه التتجية مع الدراسات السابقة التي كثفت عن التأثير الإيجابي لاستخدام البرنامج التعليمي القائم على الخرائط الرقمية في تتمية مهارات التحليل المكاني كدراسة 
(الحصري، 2016؛ الأغا وأبو سالم،Carbonell \& Hess, 2019 ولم يُعثر - على حد اطلاع الباحثين- على أي دراسات سابقة تثبت عدم فاعلية الخرائط الرقمية في تتمية مهارات التحليل المكاني. وفي ضوء ذلك تم دحض الفرضية الصفرية الرابعة، وقبول الفرضية البديلة الموجهة الرابعة التي تنص على: أنه توجد فاعلية للبرنامج التعليمي المقترح القائم على الخرائط الرقمية في تتمية مهارات التحليل المكاني لدى الطلاب الموهوبين بالمستوى الثالث الأثانوي في مدينة مكة المكرمة. الإجابة عن السؤال الثالث: هل توجد علاقة ارتباطية بين مقدار النمو في مفاهيم الأنماط والعلاقات الجغرافية ومهارات التحليل المكاني لدى الطلاب الموهوبين

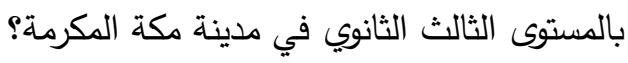

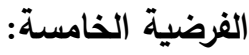
لا توجد علاقة ارتباطية ذات دلالة إحصائية عند مستوى (as0.05) بين مقدار النمو في مفاهيم الأنماط والعلاقات الجغرافية ومهارات التحليل المكاني لدى الطلاب الموهوبين بالمستوى الثالث الثانوي في مدينة مكة الثادئ الدكرمة.

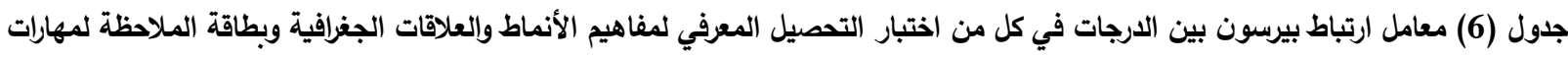

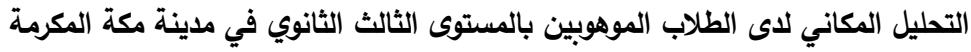

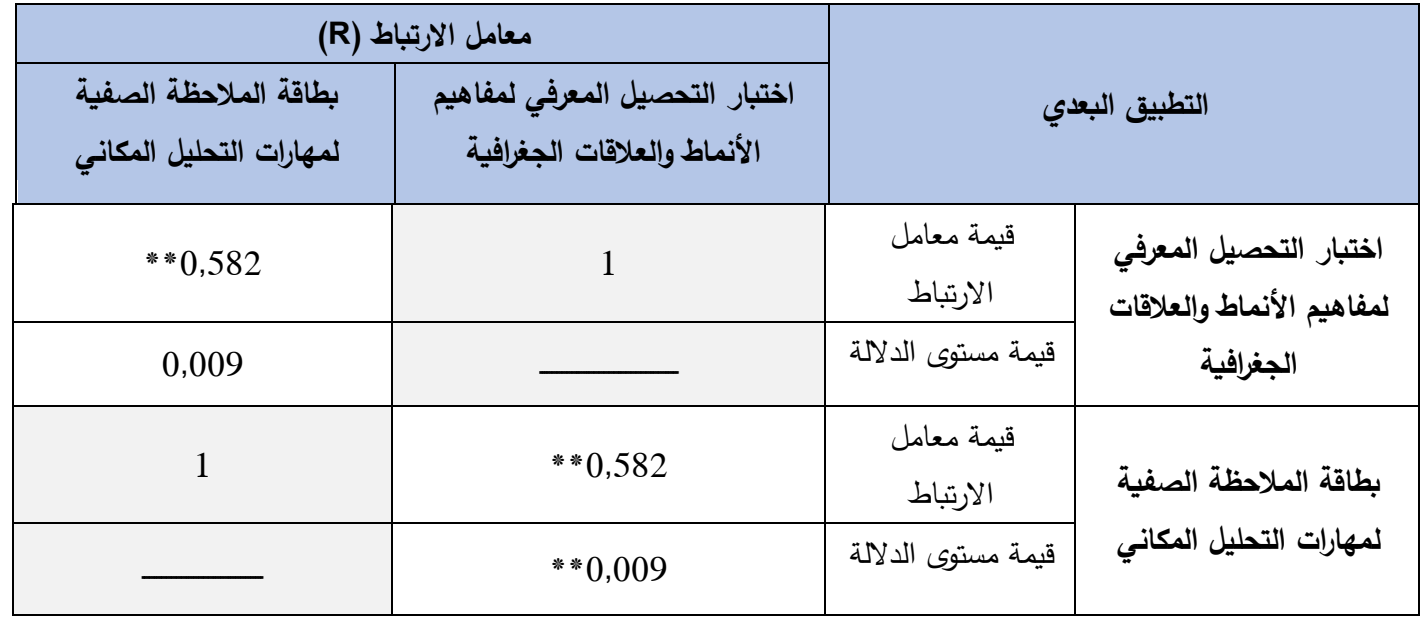

** دالة إحصائياً عند مستوى الدلالة (as0.01). يبين الجدول (6) وجود علاقة ارتباطية ذات دلالة إحصائية عند مستوى الدلالة (a<0.01) بين درجات الطلاب الموهوبين لمجموعة الدراسة في التطبيق البعدي في اختبار التحصيل المعرفي لمفاهيم الأنماط والعلاقات الجغرافية وبطاقة الملاحظة الصفية

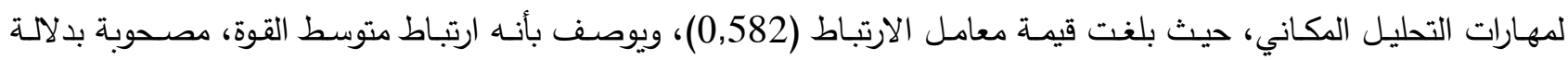

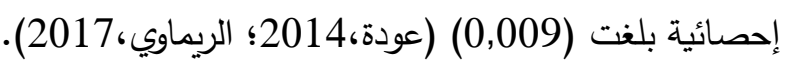

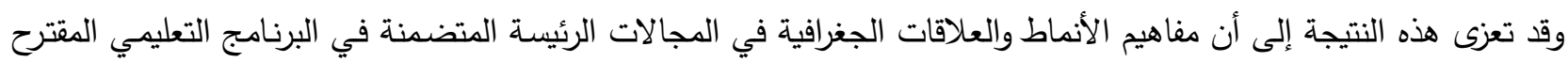
القائم على الخرائط الرقمية، قد تعلمها الطالب الموهوب وأجاد فههها، واستطاع ربطها في الواقع من خـلال الممارسات المتكررة لبرامج الخرائط الرقمية. مما انعكس إيجاباً على المهارات المرتبطة بالتحليل المكاني، لانه استطاع حينئذ أن يمارس تلك المهارات بكل جدارة، حيث أن جميع مهارات التحليل المكاني، ومفاهيم الأنماط والعلاقات الجغرافية تعتمد بشكل أساسي على بلى الخرائط الرقمية. وبالتالي استطاع الطالب الموهوب استخدام التقنيات المتقدمة للخرائط الرقمية بثكل آمن يحفظ له حقوقه، وممارسة عملية لتلك المفاهيم على هيئة أداءات مهارية. 
ووفقاً لهذه النتيجة تم رفض الفرضية الصفرية الخامسة، وقبول الفرضية البديلة الموجهة الخامسة التي تنص على أنه: توجد

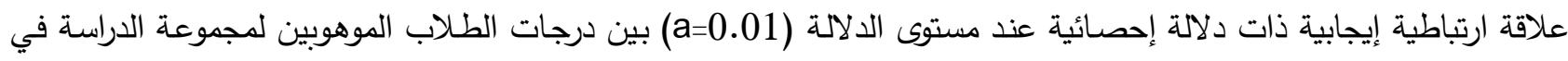
اختبار التحصيل المعرفي لمفاهيم الأنماط والعلاقات الجغرافية وبطاقة الملاحظة الصفية لدهارات التحليل المكاني. الفرضية السادسة

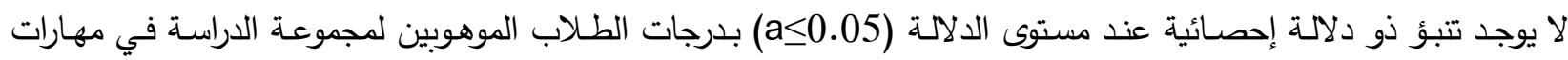

التحليل المكاني من درجاتهم في اختبار التحصيل المعرفي لدفاهيم الأنماط والعلاقات الجغرافية.

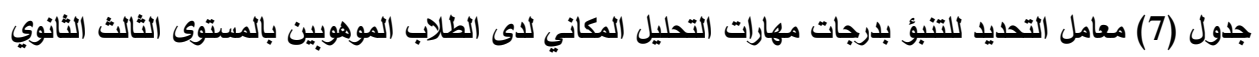

في مدينة مكة المكرمة

\begin{tabular}{|c|c|c|c|c|c|c|c|}
\hline مستوى الدلالة & $\begin{array}{c}\text { قيمة } \\
\text { (T) }\end{array}$ & الانحدار & & الدلالة & قيمة ف & التحديد & الارتباط \\
\hline 0,000 & 6,38 & 0,39 & 39,55 & 0,009 & 8,69 & 0,30 & 0,582 \\
\hline
\end{tabular}

يوضح الجدول (7) أن هنالك علاقة اعتمادية تتبؤية طردية موجبة متوسطة القوة دالة إحصائياً بين درجات الطلاب الموهوبين لمجموعة الدراسة في التطبيق البعدي في اختبار التحصيل المعرفي لمفاهيم الأنماط والعلاقات الجغرافية وبطاقة الملاحظة الصفية لمهارات التحليل المكاني، حيث بلغ معامل الارتباط (0,582). عند مستوى الدلالة (as0.01). ويفيد معامل التحديد (مربع معامل

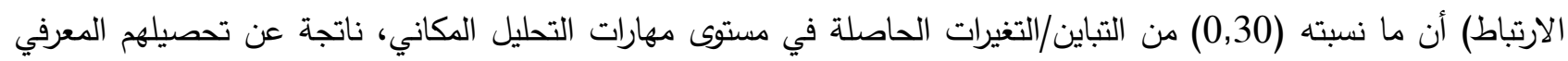

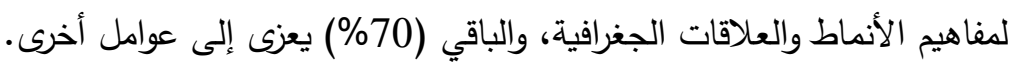

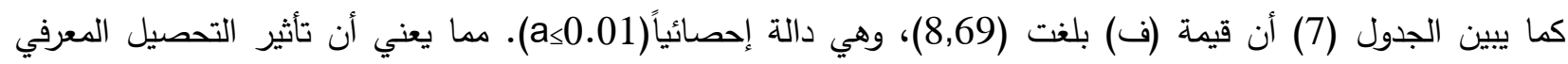
لمفاهيم الأنماط والعلاقات الجغرافية في مهارات التحليل المكاني متوسط. كما بلغت قيمة معامل الانحدار الخطي $(0,39)$ بافتراض تحييد بقية المتغيرات. مما يعني أن كل زيادة في مفاهيم الأنماط والعلاقات الجغرافية بمقدار درجة واحدة ستؤدي إلى دئى

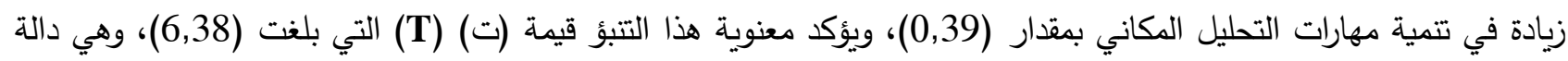
عند مستوى الدلالة (a=0.01). وبالتالي؛ يمكن التتبؤ بدرجات الطلاب الموهوبين لمجموعة الدراسة في مهارات التحليل المكاني من خلال معرفة درجاتهم في اختبار التحصيل المعرفي لمفاهيم الأنماط والعلاقات الجغرافية، حيث بلغت قيمة الجزء الثابت من درجات تحصيل المفاهيم (39,55). ومن ثم يمكن التعويض عن أي درجة سيحصل عليها أي طالب موهوب في اختبار التحصيل المعرفي لمفاهيم الأنماط والعلاقات الجغرافية بدلاً من قيمة (س)، وإيجاد مستوى الطالب (المتنبئة ص) في في بطاقة الملاحظة الصفية لمهارات التحليل المكاني. وفي ضوء ما سبق؛ تم رفض الفرضية الصفرية السادسة، وقبول الفرضية البديلة الموجهة السادسة التي تنص على أنه: يوجد تتبؤ ذو دلالة إحصائية عند مستوى الدلالة (a=0.01) بدرجات الطلاب الموهوبين لمجموعة الدراسة في مهارات التحليل المكاني من درجاتهم في اختبار التحصيل المعرفي لمفاهيم الأنماط والعلاقات الجغرافية. خلاصة الاراسة: الاستنتاجات:

1- ساعد البرنامج التعليمي المقترح في إمداد الطلاب الموهوبين بكم وافر من المعارف عن مفاهيم الأنماط الجغرافية في مجالها الكثيف والمبعثر • وكذلك ساهم في تزويدهم بعدد كبير من المعارف عن مفاهيم العلاقات الجغرافية في مجالاتها الثثلاثة. وبذلك سد البرنامج التعليمي المقترح ثغرة واسعة ولبى حاجة ماسة في البرامج التعليمية ذات الطابع التربوي عبر تتاوله لمفاهيم الأنماط والعلاقات الجغرافية، والتي تُعد من الموضوعات المتصفة بالأهمية البالغة للطلاب الموهوبين في المرحلة الثانوية. كما ساعد 791 IUG Journal of Educational and Psychology Sciences (Islamic University of Gaza) / CC BY 4.0 
البرنامج التعليمي المقترح في تقديم تلك المفاهيم المعرفية الرقمية بشكل موجز ومحسوس. مما مكن الطلاب الموهوبين من التعرف إلى مكونات المفاهيم والعلاقات وأجزائها والعلاقات التي تربط بين هذه الأجزاء، وذلك كله من خلادل أنشطة تعليمية تعلمية معتمدة على التقنية كان فيها دور المعلم هو ملاحظة أداء الطلاب الموهوبين، وتقديم المساعدة لهم للوصول إلى إجابات عن استقساراتهم. وهذا مايتقق مع نتائج الدراسات السابقة (الحصري،2016؛ عبد الحكيم،2016؛ و 2019 التي أكدت جميعها على أهمية تضمين مفاهيم الأنماط والعلاقات الجغرافية في البرامج التعليمية والمناهج الدراسية حيث تحظى بأهمية كبيرة وفاعلية عالية في تتمية مهارات التحليل المكاني، وتوسيع دائرة الثقافة الجغرافية للطلبة، ولاسيما الطلبة الموهوبين.

2- نتج عن البرنامج التعليمي المقترح تمكين الطلاب الموهوبين من ممارسة مهارات التحليل المكاني، وذلك من خلال الأنشطة التعليمية التعميّة المعتمدة على طرح الأسئلة والاستقسارات، والبحث عن إجابات مقنعة، مما كان لها دور كبير في تتمية مهارات

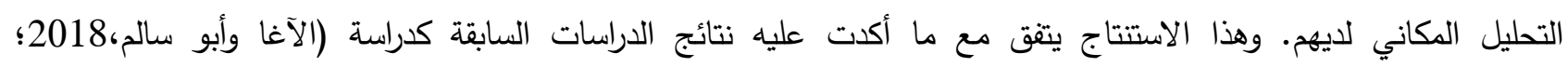
(Almairi,2019; Carbonell \& Hess, 2019 التوصيات: 1- الإفادة من البرنامج التعليمي المقترح القائم على الخرائط الرقمية في في الخطط التطويرية للبرامج التعليمية، والمناهج الدراسية من خلال إدراجها في منهج جديد للجغرافيا مخصص للطلبة الموهوبين بالمرحلة الثانوية، أو تضمين هذا البرنامج التعليمي المقترح على هيئة وحدات دراسية في كُتب الجغرافيا في المرحلة الثانوية. 2- توصي الدراسة وزارة التعليم السعودية بضرورة توفير التقنيات الجغرافية الحديثة المناسبة لتدريس مفاهيم الأنماط والعلاقات الجغرافية في مقررات الجغرافيا بمراحل التعليم العام في المملكة العربية السعودية، و منها على سبيل المثال: مرئيات الاستثعار

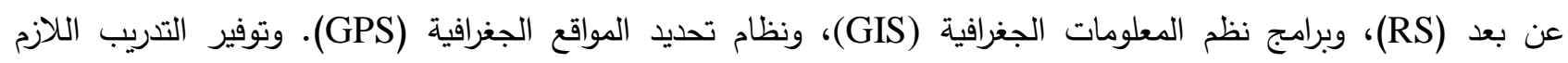
للمعلمين والمعلمات أثناء الخدمة على اتقان استخدام هذه التقنيات الجغرافية وتوظيفها في تدريسهم للجغرافيا. 3- الاهتمام بتضمين تطبيقات الخرائط الرقمية التي تساعد في تتمية مهارات التحليل المكاني وتضمينها في مقررات برامج الإعداد التربوي لمعلمي ومعلمات الجغرافيا قبل الخدمة في كليات التربية بالجامعات السعودية، وبقية الجامعات العربية. المقترحات: 1- إجراء دراسات تربوية أصيلة تعتمد على الخرائط الرقمية من خلال ربطها بتتمية ببعض المتغيرات المعتمدة (التابعة) الأخرى،

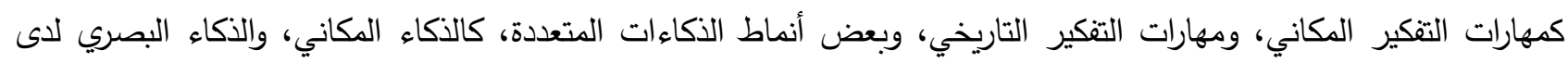
الطلبة الموهوبين بمراحل التعليم العام السعودي، ولاسيما في المرحلة الثانوية. 2- إجراء دراسات تربوية رصينة تعتمد على الخرائط الرقمية، وقياس فاعليتها في تتمية الدافعية والاتجاه نحو تعلمها لدى طلبة لعادية التعليم العام، وبشكل خاص طلبة المرحلة الثانوية في المملكة العريية السعودية.

\section{المصادر والمراجع}

\section{المراجع العربية:}

أبو دلاخ، نائلة. (2004). أثر استخدام استراتيجية خرائط الدائرة الدفاهيية على التحصيل العلمي ودافع الإنجاز وقلق الاختبار الآني والمؤجل لطلبة الصف التاسع في الكيمياء وعلوم الأرض في الددارس الحكومية في قباطية، رسالة ماجستير غير منشورة. كلية العلوم التربوية جامعة النجاح، نابلس، فلسطين. 
أبو شعيرة، خالد. ( 2009). الددخل إلى علم التربية، عمّان: مكتبة المجتمع العربي للنشر والتوزيع.

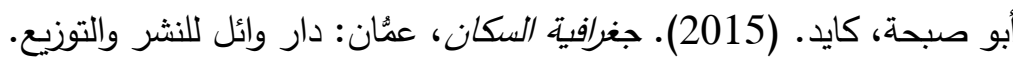
أبو علام، رجاء. (2018). التحليل الإحصائي للبينات باستخدام برنامج (SPSS)،ط4، القاهرة: دار النشر للجامعات. الأغا، عبد المعطي وأبو سالم، طلعت. (2018). أثر برنامج مقترح في تدريس الجغرافيا على تتمية مهارة قراءة الخريطة ومهارات الذكاء المكاني لاى طلاب الصف الثامن الأساسي، مجلة الجامعة الإسلامية للدراسات التربوية والنغسية- الجامعة

$$
\text { الإسلامية- غنة- فلسطين، } 26 \text { (1)، 170-199. }
$$

البناني، جابر • (2016). التحليل الدكاني، تاريخ الدخول 3/2/2019، متاح على الرابط الاتي:

http://www.gisclub.org/library/research/gis/0024.rar

الحارثي، سعد. (2015). درجة امتلاك معلمي الدراسات الاجتماعية والوطنية بالمرحلة المتوسطة لففاهيم الأنعاط والعلاقات المكانية وتوظيفاها في تدريسم في ضوء جغرافية العولمة السياسية، رسالة ماجستير غير منشورة، كلية التربية، جامعة أم

القرى، مكة المكرمة.

الحربي، عبير والأنصاري، وداد. (2019). فاعلية توظيف خرائط التفكير المحوسبة في تتمية مهارات التنكير المكاني والتحصيل المعرفي في مقرر الدراسات الاجتماعية والوطنية لاى طالبات المستوى الثاني ثانوي في مدينة مكة المكرمة، مجلة الجامعة الإسلامية للدرسات التربوية والنفسية- جامعة غنة- فلسطين، 27 (4)، 701-735. الحربي، منيرة. (2015). فاعلية استخدام الخرائط الاكترونية من خلال الثبكة العنكبوتية في تنمية مهارة قراءة الخرائط الجغرافية للى طالبات الصف الثالث متوسط، رسالة ماجستير غير منشورة، كلية التربية، جامعة طيبة، المدينة المنورة. الحصري، كامل. ( 2016). أثر تدريس الجغرافيا باستخدام الخرائط الإكترونية على التحصيل وتتمية بعض مهارات التفكير الجغرافي لدى طلاب الصف الثاني الإعدادي، مجلة جامعة طيبة للعلوم التربوية- الددينة الدنورة، 11، (1) ، 31-56. الحميد، محمد والمسند، مساعد. (2012). تطبيق منهجية التحليل المكاني باستخدام تثنيات نظم الدعلومات الجغرفية في تثيير

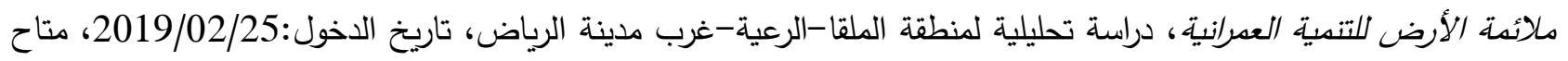
https://jassimalbanay.blogspot.com/2016/12/ على الرابط: https:/gomaa- - داوود، جمعة. (2012). المدخل الي الخرائط الرقمية، تاريخ الدخول: 20/2/2019، متاح على الرابط: dawod.blogspot.com/2015/01/blog-post_48.html الربيعة، عبد العزيز • (2012). البحث العلمي: حقيقته، ومصادرة، ومادته، ومناهجه، وكتابته، وطباعته، ومناقشته، ط6، الرياض: مكتبة العبيكان. الريماوي، عمر • (2017). بناء وتصميم الاحتبارات الومقاييس النفسية والتربوية، عُمان: دار أمجد للنشر والتوزيع. السامرائي، محمد. (2015). فلسفة الدكان في الفكر الجغرافي، عمُان: دار الصفاء للنشر والتوزيع. سويلم، أحمد. (2014). برنامج مقترح لتنمية مهارات انثاء الخرائط الرقمية والتثكير المكاني للى للى الطالب المعلم، رسالة ماجستير غير منثورة، كلية التربية، جامعة عيش شمس، القاهرة، مصر . 
الثهراني، مسعود. (2012). أثر استخدام الخرائط الإكترونية من خلال الشبكة العنكبوتية في تدربس مادة الجنرفيا على تحصيل طلاب الصف الثاني المتوسط بدحافظة بيثة و /تجاهاتهم نحوها، أطروحة دكتوراه، كلية التربية، جامعة أم القرى، مكة المكرمة. صالح، إدريس. (2017). برنامج قائم على نظم المعلومات الجغرافية لتتمية مهارات انتاج خرائط التوزيعات الكمية والانخراط في التعلم لدى طلاب كلية الآداب، مجلة دراسات في الدناهج وطرق التدريس- جامعة عين شعس -مصر، 22 (1)، 94 -

صوان، فرج. (2017). البحث العلمي: الدفاهيم، الأفكار، الطرائق والععليات، الجزائر : ابن النديم للنشر والتوزيع. عبد الحكيم، محمد. (2016). فاعلية برنامج أنشطة إثراءيه قائم على تطبيقات الخرائط التفاعلية عبر الويب في تتمية التفكير الدكاني وفهم الخريطة لدى طلاب المرحلة الثانوية، مجلة الجمعية التربوية للدراسات الاجتماعية- جامعة عين شعس -

$$
\text { مصر، } 77 \text { (5)، 65- } 115 .
$$

العزاوي، علي. (2010). نمط التوزيع المكاني لمراكز الاستيطان الريفي في قضاء الموصل، مجلة التربية والعلم- جامعة

$$
\text { الموصل - العراق، } 17 \text { (4)، } 361 \text { - } 374 .
$$

عمار ، مصطفى. (2013). الخرائط الرقمية وتتمية مهارات الجغرافيين، مجلة الكمة-مؤسسة كنوز الحكمة- الجزائر 4 (24)، $.86-72$

العميري، فها. (2004). الأنعاط المكانية لتوزيع السكان: دراسة تطبيقية على مدينة مكة الدكرمة، رسالة ماجستير غير منشورة، كلية الآداب والعلوم الإنسانية، جامعة الملك عبد العزيز، جدة، المملكة العربية السعودية. العميري، فهد. (2014). فاعلية برنامج تعليمي قائم على المعايير المعاصرة في إكساب مفاهيم التربية السكانية العالمية لمعلمي الدراسات الاجتماعية والوطنية في التعليم العام السعودي، المجلة الدولية للأبحاث التربوية- جامعة الإمارات،36 (2)، 224-

العميري، فهد. (2019). بناء برنامج تعليمي قائم على تطبيق بريزي ضمن مقررات السنة التحضيرية وقياس فاعليته في تتمية مفاهيم المواطنة الرقمية ومهاراتها لدى طلاب جامعة الملك عبد العزيز في مدينة جدة، مجلة الألسكو- الدنظمة العربية

$$
\text { للتربية والثقافة والعلوم- تونس، } 38 \text { (4)، 81-136. }
$$

العميري، فهذ والطلحي، محمد. (2019). بناء معايير مناهج الجغرافيا للطلبة الموهوبين في التعليم العام السعودي وتقنينها، مجلة

$$
\text { القادسية للآداب والعلوم التربوية- جامعة القادسية-العراق، } 18 \text { (3)، 2-28. }
$$

عودة، أحمد. (2014). القياس والتقويم في الدعملية التدريسية، ط3، عمّان: دار الأمل للنشر والتوزيع. عودة، سميح. (2014). أساسيات نظم الدعلومات الجغرفية وتطبيقاتها في رؤية جغرفية، ط2، عمّان:دار المسيرة للنشر والتوزيع والطباعة. قربة، جهاد. (2010). التطور التاريخي للفكر الجغرافي وبعض المفاهيم الخاصة، تاريخ الدخول 202/20/ 2019، متاح على http://uqu.edu.sa/page/ar/52163 الرابط: 
كاظم، شيماء وعبيد، محمد. (2014). أثر استعمال الخرائط الاكترونية والصور الفضائية عبر الثبكة العالمية في تحصيل واحتفاظ طلاب الصف الثاني المتوسط في مادة الجغرافيا، مجلة كلية التربية الأساسية- جامعة بابل- العراق 16 (1)، 455-

$$
\text { محيد، سوسن. (2014). أسس بناء الاختبارات والهقاييس النفسية والتربوية، ، عمّان: مركز ديبو لتعليم التفكير . }
$$

محمود، صلاح. (2005).برنامج قائم علي التعلم التعاوني لتدريب تلاميذ الصف الأول الاعدادي على رسم الخدمة الخريطة وقياس أثره،

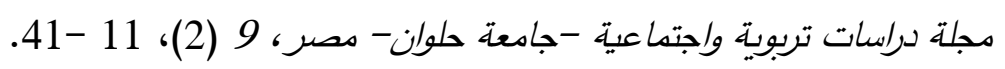

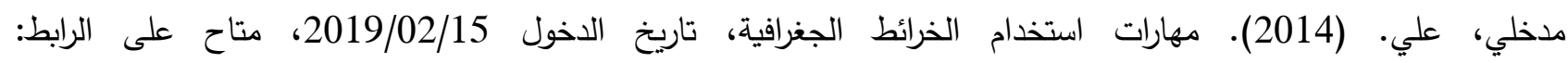
www.arabgeographers.net.

النادي، عائدة. (2007). إثراء محتوي مقرر التكنولوجيا للصف السابع الأساسي في ضوء الدعايير العالمية، رسالة ماجستير غير

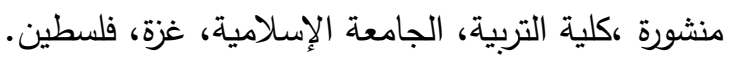
الوليعي، عبد الله. (2018). المدخل الى الجغرافيا الطبيعية والبشرية، الرياض: آفاق للنشر والتوزيع. يحيي، حسن. (2005). الجغرفية التربوية، عمَّان: دار اليازوري العلمية للنشر. يونس، إدريس. (2011). الثقافة الجغرافية وكيفية تنميتها لدى معلمي الجغرافيا، المَّنيا: منشورات كلية التربية بجامعة المَّنيامصر

Abdul Hakim, M. (2016). The effectiveness of an enrichment activities program based on the applications of interactive maps via the web in developing spatial thinking and understanding of the chart among high school students, Journal of the Educational Association for Social Studies - Ain Shams University - Egypt, 77 (5), 65-115.

Abu Allam, R. (2018). Statistical Analysis of Evidence Using (SPSS, 4th Edition, Cairo): University Press.

Abu Dalakh, N. (2004). The Impact of Using the Conceptual Circle Maps Strategy on Academic Achievement, Achievement Motivation, and the Concern of Immediate and Delayed Examination of Ninth Grade Students in Chemistry and Geosciences in Governmental Schools in Qabatia, an unpublished master's thesis. Faculty of Educational Sciences, An-Najah University, Nablus, Palestine.

Abu Sabha, K. (2015). Population Geography, Amman: Wael Publishing and Distribution House.

Abu Shairah, K. (2009). Introduction to pedagogy, Amman: Arab Society Library for Publishing and Distribution.

Agha, A. \& Abu Salem, T. (2018). The Impact of a Proposed Program in Teaching Geography on the Development of Map Reading and Spatial Intelligence Skills among Basic Eighth Grade Students, Journal of the Islamic University for Educational and Psychological Studies - Islamic University - Gaza - Palestine, 26 (1), 170-199.

Al-Azzawi, A. (2010). The spatial distribution pattern of rural settlement centers in the Mosul district, Journal of Education and Science - University of Mosul - Iraq, 17 (4), 361-374.

Albannai, J. (2016). Spatial Analysis, Date of entry 2019/2/3, available at the following link: http://www.gisclub.org/library/research/gis/0024.rar.

Alhamid, M. \& Al-Misnad, M. (2012). Application of spatial analysis methodology using geographic information systems techniques in assessing the suitability of the land for urban

795 IUG Journal of Educational and Psychology Sciences (Islamic University of Gaza) / CC BY 4.0 
development, an analytical study for the Al-Malqa area - Al-Raiah - west of Riyadh, entry date: 02/25/2019, available at the link: https://jassimalbanay.blogspot.com/ 2016/12.

Alharithi, S. (2015). The degree to which social and national studies teachers at the intermediate level possess concepts of patterns and spatial relationships and employ them in their teaching in light of the geography of political globalization, an unpublished master's thesis, College of Education, Umm Al-Qura University, Makkah Al-Mukarramah.

Alharbi, A. \& Al-Ansari, W. (2019). The effectiveness of employing computerized thinking maps in developing spatial thinking skills and cognitive achievement in the social and national studies course for secondary-level female students in the city of Makkah Al-Mukarramah, Journal of the Islamic University for Educational and Psychological Studies - Gaza University - Palestine, 27 (4), 701-735.

Alharbi, M. (2015). The Effectiveness of Using Electronic Maps Through the Internet in Developing the Skills of Reading Geographical Maps for Intermediate Third Grade Students, Unpublished Master Thesis, College of Education, Taibah University, Madinah.

Alhosary, K. (2016). The Effect of Teaching Geography Using Electronic Maps on Achievement and Development of Some Geographical Thinking Skills for Second-Year Preparatory Students, Journal of Taibah University for Educational Sciences - Al-Madinah AlMunawwarah, 11, (1), 31-56.

Alnadi, A. (2007). Enriching the content of the technology course for the seventh grade in the light of international standards, an unpublished master's thesis, College of Education, Islamic University, Gaza, Palestine.

Al-Omiri, F. (2004). Spatial Patterns of Population Distribution: An Applied Study on the City of Makkah Al-Mukarramah, Unpublished Master Thesis, College of Arts and Humanities, King Abdulaziz University, Jeddah, Kingdom of Saudi Arabia.

Al-Omiri, F. (2014). An educational program's effectiveness based on contemporary standards in imparting global population education concepts to social and national studies teachers in Saudi public education, International Journal of Educational Research - United Arab Emirates University, 36 (2), 224-258.

Al-Omiri, F. (2019). Building an educational program based on the application of Prezi within the preparatory year curricula and measuring its effectiveness in developing the concepts and skills of digital citizenship among students of King Abdulaziz University in the city of Jeddah, Alsco Magazine - Arab Organization for Education, Culture and Science - Tunis, 38 (4), 81-136.

Al-Omiri, F. \& Al-Talhi, M. (2019). Building and codifying geography curriculum standards for gifted students in Saudi public education, Al-Qadisiyah Journal of Arts and Educational Sciences - Al-Qadisiyah University - Iraq, 18 (3), 2-28.

Alsamurai, M. (2015). Place Philosophy in Geographical Thought, Amman: Dar Al-Safa for Publishing and Distribution.

Al-Shahrani, M. (2012). Using electronic maps through the Internet in teaching geography on the achievement of second-grade intermediate students in Bisha governorate and their attitudes towards it, Ph.D. thesis, College of Education, Umm Al-Qura University, Makkah AlMukarramah.

Al-Rimawi, O. (2017). Building and designing psychological and educational tests and standards, Amman: Amjad House for Publishing and Distribution.

Alwalei, A. (2018). Introduction to Physical and Human Geography, Riyadh: Prospects for publication and distribution.

Ammar, M. (2013). Digital maps and developing geographers' skills, Al-Hikma Magazine - The Foundation for the Wisdom Treasures - Algeria 4 (24), 72-86.

Dawood, G. (2012). Digital Maps portal, entry date: 2019/2/20, available at: https://gomaadawod.blogspot.com/2015/01/blog-post_48.html. 
Kazem, S. \& Obaid, M. (2014). The effect of using electronic maps and satellite images via the global network on the achievement and retention of second-grade intermediate students in the subject of geography, Journal of the College of Basic Education The University of Babylon Iraq $16(1), 455-478$.

Kirbah, J. (2010). The historical development of geographical thought and some particular concepts, entry date 02/20/2019, available at the link: http://uqu.edu.sa/page/ar/52163.

Madkhali, A. (2014). Skills of using geographical maps, entry date 02/15/2019, available at www.arabgeographers.net

Mahmoud, S. (2005). Teaching and Learning Geography in the Information Age, Cairo: The World of Books.

Mahmoud, S. (2005). A program based on cooperative learning to train first-grade middle school pupils on drawing a map and measuring its impact, Journal of Educational and Social Studies Helwan University - Egypt, 9 (2), 11-41.

Majeed, S. (2014). Foundations of building psychological and educational tests and standards, Amman: Depot Center for Teaching Thinking.

Odah, A. (2014). Measurement and Evaluation in the Teaching Laboratory, 3rd Edition, Amman: Dar Al-Amal for Publication and Distribution.

Odah, S. (2014). Fundamentals of Geographic Information Systems and their Applications in a Geographical Vision, 2nd Edition, Amman: Dar Al-Masirah for Publishing, Distribution, and Printing.

Rabiah, A. (2012). Scientific Research: Its Truth, Confiscation, Material, Methods, Writing, Printing, and Discussion, 6th Edition, Riyadh: Obeikan Library.

Saleh, I. (2017). A program based on geographic information systems to develop quantitative distributions maps and engage in learning among students of the Faculty of Arts, Journal of Studies in Curricula and Teaching Methods - Ain Shams University - Egypt, 22 (1), 94 - 128.

Sawan, F. (2017). Scientific Research: Concepts, Ideas, Methods and Processes, Algeria: Ibn Nadim for Publishing and Distribution.Sweilem, Ahmed. (2014). A proposed program to develop digital maps and spatial thinking skills among the student-teacher, an unpublished master's thesis, College of Education, Aich Shams University, Cairo, Egypt.

Yahya, H. (2005). Educational Geography, Amman: Al-Yazouri Scientific Publishing House.

Yunus, I. (2011). Geographical culture and how to develop it among geography teachers, Minya: Publications of the Faculty of Education at the University of Minya - Egypt.

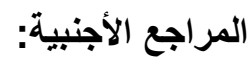

Alomairi, F. (2019). Developing Undergraduate Students Geogrephy Learning Skills During Fieldwork and their Attitudes Towards it, Psycholohical and Educational Research center, 62, (16), 36-57.

Buang, N. Zin, A. \& Zakaria. M. (2011). Exploring Spatial Relationships for Knowledge Discovery in Spatial Dat,International Conference on Computer Engineering and Applications IPCSIT, Singapore: IACSIT Press.

Carbonell, C. \& Hess,M. Stephany. (2019). 3D Landform Modeling to Enhance Geospatial Thinking , International Journal of Geo-Information, 65 (8), 2-15.

Choen, L.\& Mannion, L.\& Morrisonn, K. (2011). Reseerch methods in education, 7 th ed London: Routiedhe Falmer.

Cooper, J. (1981). Measurinh dehavior (The Charles E. Merrill series on brhavioral techniques in the classroom), Second Edition, Columbus, Ohio: Merrill.

Gaith, G. (2003). Relationship between reading attitudes, achievement and learners perceptions of their Jigsaw 2 cooperative learning experience, Reading Psychology, 24 (2), 1-6. 
Kaufman, M. (2004). Using ISpatial-Temporal Primitives to Improve Geography Skills for Preservice Teachers, Journal of Geography, 103 (4), 171 -181.

Kerri, S. (2010). Google Earth in the Middle School Geography Classroom: Its Impact on Spatial Literacy and Place Geography Understanding of Students, For the degree of Doctor of Philosophy, University of North Dakota.

Strachan, C.\& Mitchell J. (2014). Teachers' Perceptions of Esri Story Maps as Effective, Review of International Geographical Education Online 4 (3), 190-220.

Sturz, B. Kelly, D. \& Brown, M. (2009). Facilitation of learning spatial relations among locations by visual cues: generality across spatial configurations, Amin Cogn, 13 (2), 341- 349 .

Sweilem, A. (2014). A proposed program to develop the skills of creating digital maps and spatial thinking among the student teacher, an unpublished master's thesis, College of Education, Aich Shams University, Cairo, Egypt.. 